\title{
Resistencia química del hormigón \\ I. Estudio de dos cementos portland frente al agua de mar
}

DEMETRIO GASPAR-TEBAR y JOSE LCIS SAGRERA-MORENO

Drs. en Ciencias Quimicas

IETCC

\section{INTRODUCCION}

El comportamiento de los morteros y hormigones sometidos a la acción del agua de mar ha sido objeto de numerosos trabajos como consecuencia de la gran cantidad de obras marítimas construidas a base de hormigón en masa y armado; de aquí, que sea un tema que ha preocupado y sigue interesando no sólo desde un punto de vista tecnológico o constructivo, sino científico, para conocer las causas que producen su destrucción y poder tomar, en su caso, las medidas oportunas.

El hormigón es un material heterogéneo, de propiedades muy variables que dependen. fundamentalmente, de las características de los componentes, de sus cantidades, de su puesta en obra, del curado y conservación, del medio en donde va a estar trabajando, etc.

El gran desarrollo que la técnica ha experimentado hace que en el diseño de las estructuras ocupe un lugar fundamental su comportamiento frente a los posibles agentes agresivos; es decir, su durabilidad qumica y las medidas preventivas que se deben tomar.

El mecanismo de la destrucción del hormigón por el agua de mar es muy complejo, ya que intervienen gran número de parámetros (mecánicos, físicos, químicos, biológicos y atmosféricos) que complican, por una parte, el conocimiento de dicha destrucción y despiertan, por otra, el interés de aquellas personas relacionadas con esta faceta de la ciencia.

En las construcciones marítimas a base de hormigón hay que distinguir tres casos, según que el hormigón se encuentre sumergido permanentemente en agua de mar, en la zona de oleaje o mareas o fuera del agua.

El desarrollo de las costas de España y la naturaleza de los suelos hacen que los estudios relacionados con la resistencia química de los cementos, morteros y hormigones haya sido uno de los programas permanentes de investigación del Instituto Eduardo Torroja de la Construcción y del Cemento.

En el presente trabajo, con el que iniciamos una serie de publicaciones, se da cuenta del comportamiento de morteros (1:3) hechos con dos cementos portland, fabricados por la industria española, frente al agua de mar desde un punto de vista de las reacciones que pueden tener lugar (variación de la concentración iónica del medio y de la composición estructural de la pasta) y de la influencia en las características físicas y mecánicas de los morteros, cuando se encuentran sumergidos en dicha agua durante 56 días, después de haberlos curado en agua filtrada durante 21 días. 


\section{ESTUDIO BIBLIOGRAFICO}

Los problemas planteados por el ataque químico de los morteros y hormigones por agua de mar, natural o artificial, ha sido objeto de numerosos trabajos que han mostrado que su estabilidad depende, fundamentalmente, de tres factores: compacidad, dosificación y tipo de cemento. Los dos primeros son los que más influyen, de tal modo que los hormigones compactos, fuertemente dosificados y hechos con bajas relaciones $a / c$ son los que mejor resisten.

Idorn (1) indica que los trabajos experimentales se iniciaron en el año 1756 por Smeaton cuando preparaba la construcción del faro de Eddystone.

Bogue (2), Lea y Desch (2) y Biczok (4), entre otros, hacen un resumen cronológico de los ensayos realizados en diferentes países, que se iniciaron a finales del siglo XIX.

Bogue (2) recoge un determinado número de investigaciones efectuadas sobre el comportamiento de los cementos frente a diversos medios agresivos, incluidas las disoluciones de sulfatos en general, bien en medios naturales o artificiales, poniendo de manifiesto que el comportamiento de los cementos es función del contenido de $\mathrm{C}_{3} \mathrm{~A}$. Bates, Phillips y Wig, según Bogue, probaron que probetas de hormigón cuidadosamente fabricadas, expuestas a la acción del agua de mar, no muestran descomposición alguna.

Lea y Desch (5) realizan un estudio amplio sobre la acción que ejercen las aguas sulfatadas de mar en los cementos y el mecanismo de las reacciones que tienen lugar. Los autores destacan la influencia de los iones magnesio, sulfato y cloruro en las reacciones químicas, así como sobre la estabilidad del sulfoaluminato de calcio y sobre la solubilidad del $\mathrm{Ca}(\mathrm{OH})_{2}$ y del $\mathrm{CaSO}_{4}$, señalando que un hormigón atacado progresivamente por agua de mar muestra un aumento creciente de $\mathrm{Mg}(\mathrm{OH})_{2}$, un descenso de $\mathrm{Ca}(\mathrm{OH})_{2}$ y un aumento de $\mathrm{CaSO}_{4}$, seguido de una disminución posterior; después de largos períodos de tiempo, el conjunto de reacciones puede dar lugar a la formación de silicatos de magnesio. La velocidad del ataque químico es función de la temperatura y del tipo de cemento.

Nicol (6) considera que el ataque químico producido por agua de mar se debe a la acción de los iones $\mathrm{Mg}(\mathrm{II})$ y $\mathrm{SO}_{4}$ (II) que, con el $\mathrm{Ca}(\mathrm{OH})_{2}$, dan $\mathrm{CaSO}_{4}$ y $\mathrm{Mg}(\mathrm{OH})_{2}$; los silicatos de calcio hidratados pueden llegar a dar, por descomposición, cal hidratada y sílice, y el aluminato formar sulfoaluminato hidratado, que es inestable en presencia de sulfato de magnesio, proporcionando, finalmente, sulfato de calcio, alúmina hidratada e hidróxido de magnesio; hechos que también recogen Lea y Desch (5). Flintg y Wells, según Nicol resaltan la influencia que ejerce el contenido de $\mathrm{C}_{3} \mathrm{~A}$ del clínker y el efecto favorable que produce la adición de puzolanas.

Duriez (7) determina el efecto de la acción del agua de mar y de las aguas agresivas sobre cales y cementos, centrándose en el comportamiento de morteros y hormigones y, de un modo especial, del hormigón armado; considera que este ataque es parecido al de las aguas selenitosas, aunque menos nocivo, ataque que disminuye al estar carbonatada la superficie que obstaculiza, en parte, la difusión externa del $\mathrm{Ca}(\mathrm{OH})_{2}$ y la penetración de los iones presentes en el mar.

Campus (8) informa sobre los trabajos llevados a cabo en Bélgica, canal de acceso a Ostende, para conocer el comportamiento de morteros y hormigones expuestos a la acción del agua de mar durante 20 años (1934 a 1954), manifestando que en las probetas sumergidas se ha observado que la acción química ejerce ciertos efectos, sobre todo en el caso de los cementos ricos en cal y en las probetas poco compactas; mientras que en las situadas en el nivel medio influyen las condiciones atmosféricas, de un modo especial el hielo, las acciones mecánicas y los efectos biológicos. Los hormigones compactos, inde- 
pendientemente del cemento utilizado, resisten bien y llegan a adquirir resistencias mecánicas más elevadas que cuando se conservan bajo agua; los cementos a base de escoria granulada básica, pobres de cal, son muy adecuados para trabajos en el mar. Estas recomendaciones se han recogido en la Nota Informativa Técnica n. 57 del "Centre Scientifique et Technique de la Construction" de Bélgica (9).

García de Paredes (10) hace un estudio profundo sobre la durabilidad del hormigón, discutiendo las causas fisicoquímicas que producen la alteración del mismo en diferentes medios agresivos. Las acciones químicas del agua de mar sobre los hormigones se pueden resumir, según dicho autor, como el resultado de varias reacciones: extracción del $\mathrm{CaSO}_{4}$ debido al incremento de la solubilidad por la presencia de iones cloruro; extracción de los iones calcio y sustitución por hidróxido de magnesio; reacción del sulfato de magnesio con el óxido de calcio; formación expansiva del sulfoaluminato de calcio y posterior descomposición dando alúmina hidratada, hidróxido de magnesio y sulfato de calcio, y descomposición de los silicatos hidratados con producción de sílice hidratada, yeso y óxido de magnesio.

Brocard y Cirodde (11) (12) dan cuenta de los resultados correspondientes al programa de trabajo, iniciado hace varios años, sobre la resistencia frente al agua de mar de los hormigones fabricados con tres tipos de cemento (cemento portland con $\mathrm{C}_{3} \mathrm{~A} \leqslant 8 \%$ y con $\mathrm{C}_{3} \mathrm{~A} \geqslant 12 \%$, cemento siderúrgico con un contenido de escoria superior al $80 \%$ y cemento metalúrgico sobresulfatado), con el fin de seleccionar los cementos más apropiados.

La degradación de los hormigones por agua de mar es consecuencia de varias causas que, a su vez, dependen de las condiciones atmosféricas y en particular de la temperatura. El ataque químico de las probetas sumergidas en agua de mar es relativamente lento tanto para los hormigones hechos a base de cemento portland con $\mathrm{C}_{3} \mathrm{~A} \leqslant 8 \%$, como para los fabricados con el cemento siderúrgico y el metalúrgico. En los hormigones semisumergidos la acción química es relativamente secundaria, predominando la degradación física producida por la cristalización de sales.

Lyse (13) describe los ensayos llevados a cabo durante 20 años en "Concrete Laboratory Norway's Institute of Technology", dando cuenta de la durabilidad del hormigón cuando se encuentra sometido a la acción del hielo y deshielo en el mar, resaltando la influencia favorable que ejercen los agentes introductores de aire.

Courcambeck, Duhoux y Tessier (14) ensayan el comportamiento de hormigones de buena calidad, fabricados con cinco tipos de cemento, sometidos a la acción del mar en el estuario de la Rance, cerca de St. Malo; no han observado alteraciones.

Wesche (15) determina la influencia del volumen de poros de la pasta endurecida de cemento hidratado sobre la resistencia de hormigones expuestos a la acción del agua de mar durante 25 años. Los resultados han mostrado que, cuando dicho volumen es inferior al $30 \%$, el hormigón, independientemente de los cementos ensayados, apenas si es atacado.

La clasificación que de los cementos estudiados hace Wesche, según su resistencia química al agua de mar, es la siguiente: cemento aluminoso, cementos siderúrgicos con 60/70\% y $30 \%$ de escorias, cemento férrico con una relación $\mathrm{Al}_{2} \mathrm{O}_{3} / \mathrm{Fe}_{2} \mathrm{O}_{3}=0,44$ y cemento portland; el autor estudia la influencia favorable que produce la adición de trass.

Wesche y Mängel (16) han experimentado la influencia que ejerce la temperatura en el ataque de morteros por agua de mar artificial, preparada con concentraciones superiores de sales.

En condiciones climáticas rigurosas, como sucede en Noruega, la acción del hielo es la causa principal de las lesiones producidas en el hormigón. 
Gjörv, Gukild y Sundh (17) han observado el comportamiento de pilares de hormigón colocados durante 27 años en la zona de mareas. Al parecer existe una correlación entre el ataque químico de los hormigones y los contenidos decrecientes de $\mathrm{C}_{3} \mathrm{~A}$ de los cementos; la acción del hielo ha sido el factor que más ha contribuido a la destrucción de los pilares.

Gjörv (18) hace un estudio crítico sobre el mecanismo del ataque químico del hormigón por agua de mar. Considera que la formación de los compuestos voluminosos a base de yeso y sulfoaluminatos de calcio depende, en gran parte, de las concentraciones de los iones sulfato y cloruro en el mar y de la composición mineralógica del cemento, de tal modo que, según los contenidos de $\mathrm{C}_{3} \mathrm{~A}$ del cemento y del ion sulfato del medio, la cantidad formada de dichos compuestos puede ser baja o nula; por otra parte, gran cantidad de iones cloruro puede reducir el efecto del ataque del ion sulfato por incrementar la solubilidad de las sales voluminosas; así mismo la solubilidad del hidróxido $y$ del sulfato de calcio se incrementan.

Smolczyk (19) señala que el ataque del hormigón por los iones sulfato presentes en el agua de mar es lento dada la elevada concentración de iones cloruro. En la zona de las mareas se produce un ataque considerable por la cristalización de sales. Los cementos siderúrgicos, según Smolcyk, han mostrado siempre un elevado grado de resistencia.

Duhoux y Tessier (20) han probado que los hormigones fabricados con cementos siderúrgicos conteniendo un $70 \%$ de escoria, estudiados a escala de laboratorio para la fábrica maremotriz de la Rance, presentan buena resistencia a los sulfatos, baja retracción hidráulica y pequeño calor de hidratación.

Duriez (21) trata de las propiedades y utilización de los cementos metalúrgicos puzolánicos; considera que son particularmente eficaces para la protección de las armaduras de obras marítimas contra la corrosión, debido a la formación de alúmina, sílice y geles alumino-silícicos durante las reacciones de hidratación. A pesar de la disminución de $\mathrm{pH}$, el autor opina que el $\mathrm{Ca}(\mathrm{OH})_{2}$, liberado por el cemento en los primeros días, es suficiente para formar una capa pasivante del acero.

Rio y Celani (22) consideran la acción beneficiosa que ejercen las puzolanas sobre la resistencia química de los cementos puzolánicos frente a las disoluciones de sulfatos; el mecanismo de esta resistencia química no se conoce perfectamente. Por otra parte, indican que los cementos obtenidos a partir de un clínker de tipo férrico, con un contenido elevado de sílice, y una puzolana rica en sílice reactiva presentan gran resistencia química, habiéndose utilizado para reparar obras marítimas deterioradas.

Temutasse, van Bemst y de Keyser (23) determinan la composición química y mineralógica de los productos hidratados formados en los morteros y hormigones sumergidos en el mar del Norte (Ostende); en realidad es el complemento del trabajo de Campus (8). Según los autores se produce una disminución de $\mathrm{CaO}$, especialmente en aquellos cementos que tienen una cantidad elevada, un aumento de MgO como consecuencia de la precipitación de $\mathrm{Mg}(\mathrm{OH})_{2}$ y, en general, un ligero aumento de $\mathrm{SO}_{3}$. Por otra parte, se ha observado que los morteros están fuertemente carbonatados, habiendo detectado calcita y aragonito; también han probado la esistencia de ettringita que, en contra de la opinión general, consideran que es estable en el agua de mar.

Sousa Coutinho y Peres Rodrigues (24) sostienen que la formación de un revestimiento de carbonato de calcio es decisivo para proteger el hormigón sometido a la acción del agua de mar; los ensayos se han efectuado en las condiciones climáticas de las costas portuguesas con hormigones fabricados con cemento portland y puzolánico.

Nielsen (25) resume los trabajos realizados en obras marítimas de los países nórdicos, teniendo en cuenta las condiciones climáticas, las características del agua de mar, los ciclos de hielo y deshielo, la acción de las mareas, la reacción álcali-áridos, la influencia del 
tipo de cemento, etc. El ataque químico producido por las aguas frías de estos mares se considera despreciable.

Kuenning (26) recoge los trabajos realizados por Mather (27), en donde se discute el mecanismo del ataque por agua de mar sintética, así como la acción de disoluciones de $\mathrm{MgSO}_{4}$ y de los iones $\mathrm{CO}_{3}$ (II), $\mathrm{HCO}_{3}$ (I), $\mathrm{Cl}$ (I) y de los correspondientes a los metales alcalinos. Según Kuenning los morteros hechos con cemento del tipo $\mathrm{V}$ de las normas ASTM $\left(\mathrm{C}_{3} \mathrm{~A} \leqslant 5 \%\right)$ son los que presentan mejor resistencia química.

Mather señala que el empleo de puzolanas en la fabricación de hormigones expuestos a la acción del agua de mar, ha sido ampliamente difundido porque incrementa la resistencia al ataque químico; el cemento portland que se debe utilizar es el correspondiente al tipo II de las normas ASTM $\left(\mathrm{C}_{3} \mathrm{~A} \leqslant 8 \%\right)$.

Kremser (28) ensaya la influencia de la adición de trass a los hormigones para obras marítimas, con objeto de aclarar la discrepancia entre las conclusiones del fascículo número 102 (1950 y 1955) de la Comisión Alemana para el Hormigón Armado y la experiencia práctica. Según el autor esta adición mejora el comportamiento de los cementos siderúrgicos.

Dutron y Plisnier (29) dan cuenta de los trabajos realizados desde 1940 a 1967 para determinar el comportamiento mecánico-resistente de morteros y hormigones frente al agua de mar y a diversos medios agresivos.

Kalousek y Benton (30) investigan el mecanismo del ataque químico del agua de mar sobre las pastas hidratadas de tres cementos (tipo I, II y V, con $\mathrm{C}_{3} \mathrm{~A}=0$, de las normas ASTM) y ponen de manifiesto que se forman dos tipos de ettringita: una asociada con la expansión que aparece en las pastas de cemento del tipo I, y otra que se encuentra en las pastas del cemento con $\mathrm{C}_{3} \mathrm{~A}=0$ que no produce dicha expansión. $\mathrm{A}$ la vez el ion cloruro penetra en las pastas de los tres cementos formando los cloroaluminatos correspondientes, favoreciendo, en determinadas condiciones, la solubilidad de la ettringita; los fenómenos mencionados transcurren de modo distinto según el tipo de cemento.

Steopoe (31) trata sobre la acción que produce el agua de mar en los hormigones, así como sobre las modificaciones que experimentan, tanto en lo referente a su composición química (descalcificación, formación de hidróxido de magnesio, de dióxido de silicio geliforme, etc.) como a sus características resistentes.

Biczok (32) estudia la acción corrosiva que produce el agua de mar sobre distintos cementos, considerando que es mucho más lenta que la producida por las aguas idulces sulfatadas. El proceso de destrucción del hormigón es consecuencia de un gran número de reacciones, resaltando que la presencia de iones sodio y cloruro facilitan la solubilidad de los hidróxidos de calcio y de magnesio, por una parte, y que la posibilidad de formación de sulfoaluminato de calcio es función de la concentración de iones sulfato y cloruro en el agua de mar y de la composición mineralógica del clínker, especialmente de su contenido en $\mathrm{C}_{3} \mathrm{~A}$.

Gjörv (33) da cuenta de los resultados obtenidos, durante 25-30 años, con más de 2.500 probetas de hormigón hechas con 18 cementos distintos, expuestas a la acción del agua de mar en Trondheim Harbor (Noruega); resultados que han permitido deducir que existe una gran variación en el comportamiento de dichos hormigones, influyendo más en la durabilidad del hormigón su fabricación, contenido de cemento, relación $a / c$, etc. También se ha visto la importancia que tiene el bajo contenido de $\mathrm{C}_{3} \mathrm{~A}$ de los cementos portland estudiados y la influencia favorable de la adición de trass; el efecto del trass es más pronunciado en los cementos portland con mayor cantidad de $\mathrm{C}_{3} \mathrm{~A}$ y en los cementos siderúrgicos con mayor contenido de escorias. 
Peltier (34) trata estadísticamente los resultados obtenidos en el trabajo iniciado en 1904 para examinar el comportamiento frente al agua de mar de 120 cementos, con los que se fabricaron morteros de diversas dosificaciones, que se conservaron, en parte, en recipientes llenos con agua de mar, colocados en el laboratorio, y el resto en otros recipientes situados al aire en comunicación con el mar. $\mathrm{Al}$ parecer, el contenido de $\mathrm{C}_{3} \mathrm{~S}$ en los cementos portland no ha tenido influencia en su comportamiento, mientras que el contenido de $\mathrm{C}_{3} \mathrm{~A}$ ha sido netamente significativo por lo que, según Peltier, la especificación americana al limitar el contenido de $\mathrm{C}_{3} \mathrm{~A}$ a $8 \%$ responde mejor que la especificación francesa, hecho que también confirma Regourd (39) y la Portland Cement Association.

Basilio (35), en sus conferencias pronunciadas en la Universidad Nacional de Brasilia y en el Club de Ingeniería de Río de Janeiro sobre la destrucción del hormigón en medios agresivos, considera algunos casos relacionados con el ataque producido por agua de mar. Menciona que para obras marítimas o sujetas al ataque de aguas que contengan sulfatos, se pueden usar cementos con bajo contenido de aluminatos, máximo de $8 \%$ de $\mathrm{C}_{3} \mathrm{~A}$ en los cementos de moderada resistencia a los sulfatos y de $4 \%$ para los de alta resistencia.

Gerwick (36) señala que el pH de la pasta de cemento disminuye por la presencia de iones cloruro, por lo que los fenómenos de corrosión de armaduras se ve facilitada y acelerada en zonas de clima cálido. La protección interna del hormigón al ataque químico por agua de mar, se puede conseguir utilizando cementos portland de bajo contenido de elementos alcalinos (menor de 0,65\% de $\mathrm{K}_{2} \mathrm{O}+\mathrm{Na}_{2} \mathrm{O}$ ), moderado de $\mathrm{C}_{3} \mathrm{~A}$ (del 6 al $8 \%$ ), áridos apropiados, hormigón bien compactado con superficies lisas, dosificaciones ricas en cemento, relaciones $a / c$ bajas, etc.

El cemento portland de bajo contenido en $\mathrm{C}_{3} \mathrm{~A}$, según el Handbook of Concrete Engineering (37), es el indicado para la confección de hormigones resistentes al ataque químico producido por agua de mar. Los cementos puzolánicos y los siderúrgicos no resisten siempre a las disoluciones de sulfatos o al agua de mar, su comportamiento depende del contenido de $\mathrm{C}_{3} \mathrm{~A}$ en la fracción clínker; por otra parte, si la fracción de clínker portland tiene menos del $8 \%$ de $\mathrm{C}_{3} \mathrm{~A}$, el reemplazamiento parcial por puzolana o por escoria de horno alto no es motivo suficiente para que proporcione un incremento de dicha resistencia.

Regourd, Hornain y Mortureux (38) estudian el papel importante que juega el sistema de cristalización del $\mathrm{C}_{3} \mathrm{~A}$ en la resistencia química de los cementos frente al agua de mar, empleando para ello la microscopía electrónica, microsonda electrónica y difracción de rayos $\mathrm{X}$. En este trabajo se utilizan mezclas sintéticas de $\mathrm{C}_{3} \mathrm{~S}$ y $\mathrm{C}_{3} \mathrm{~A}$, y tres cementos, uno de escoria y otros dos portland, uno con $14 \%$ de $\mathrm{C}_{3} \mathrm{~A}$ tetragonal y $2 \%$ cúbico, y otro con $7 \%$ de $\mathrm{C}_{3} \mathrm{~A}$ cúbico.

Regourd (39) resalta que las numerosas investigaciones realizadas sobre la resistencia química de los morteros y hormigones al agua de mar han mostrado que la estabilidad depende de tres factores: compacidad, dosificación de cemento y resistencia química del mismo, siendo los dos primeros los más importantes. En el momento que hormigones compactos y fuertemente dosificados empiezan a degradarse superficialmente es cuando el cemento debe tener una resistencia química elevada.

El mecanismo de la acción del agua de mar sobre los hormigones es muy complejo. Según Regourd intervienen un número determinado de parámetros que todavía no se han podido aislar, siendo el contenido de $\mathrm{C}_{3} \mathrm{~A}$ y de $\mathrm{Ca}$ (II) de los cementos los dos factores esenciales; la ettringita formada no es siempre proporcional al hinchamiento de los hormigones. Considera, como Peltier (34), que la especificación americana es más segura que la francesa y que no hay que ignorar el papel que juegan la granulometría y la crista- 
lización de las diferentes fases del clínker, la interacción $\mathrm{C}_{3} \mathrm{~S}-\mathrm{C}_{3} \mathrm{~A}$, el contenido de $\mathrm{C}_{4} \mathrm{AF}$ que, como el $\mathrm{C}_{3} \mathrm{~A}$, da ettringita en presencia de sulfatos, así como el diferente comportamiento de las tres formas cristalinas del $\mathrm{C}_{3} \mathrm{~A}$.

Collepardi, Guella y Valente (40) desarrollan un trabajo para conocer el ataque químico del hormigón, especialmente por agua de mar, fabricado con diferentes tipos de cemento (portland con $7,5 \%$ de $\mathrm{C}_{3} \mathrm{~A}$, puzolánico y de escorias). La adición de productos que reduzcan la relación a/c incrementa la resistencia mecánica y la durabilidad de los hormigones hechos con cemento puzolánico y de escorias.

Della Libera (41) estudia los requisitos de seguridad de las estructuras marítimas a base de hormigón armado, para lo cual considera el comportamiento de los cementos portland normales frente al agua de mar, los problemas que plantea la corrosión de las armaduras y de los conglomerados, así como la protección de dichas estructuras.

Según Della Libera, los cementos férricos-puzolánicos, compuestos a base de clínker con contenido nulo de $\mathrm{C}_{3} \mathrm{~A}$ y una cantidad apropiada de puzolana, responden a los requisitos de resistencia química frente al agua de mar; los cementos puzolánicos, constituidos por clínker portland con un contenido de $\mathrm{C}_{3} \mathrm{~A}$ comprendido entre 5 y $9 \%$ y puzolana activa, presentan suficiente resistencia química; los cementos siderúrgicos muestran una cierta resistencia química que es función del contenido de $\mathrm{C}_{3} \mathrm{~A}$ del clínker y de $\mathrm{Al}_{2} \mathrm{O}_{3}$ de la escoria, y los cementos sobresulfatados presentan un elevado grado de resistencia química. En ausencia de los cementos mencionados se puede usar el cemento portland similar al tipo V (ASTM), con un bajo grado de saturación de cal para limitar la posibilidad del lavado (41).

Dzulynski (42), en el documento RILEM-4CDC, estudia el comportamiento de los hormigones frente a diversos medios agresivos. El agua de mar produce una descalcificación del cemento, fenómeno que eventualmente va acompañado de una colmatación de los poros por precipitación de $\mathrm{Mg}(\mathrm{OH})_{2}$; la elección del cemento resistente debe hacerse entre los portland con bajo o nulo contenido de $\mathrm{C}_{3} \mathrm{~A}$, los siderúrgicos con fuerte contenido de escorias y bajos de cal y los sobresulfatados.

Locher (43), en su trabajo sobre la influencia que ejercen los iones cloruro y los hidrogenocarbonatos en el ataque del hormigón por los sulfatos, confirma que el agua de mar tiene un efecto agresivo significativamente menor que el de una disolución de sulfato de sodio o de magnesio que tenga la misma concentración de ion sulfato; por otra parte, ha estudiado si dichos iones son los responsables de este comportamiento diferente, habiendo demostrado que el ataque producido por los sulfatos se incrementa por la adición de cloruros y se reduce por la de hidrógenocarbonatos. La presencia de cloruros aumenta la soIubilidad de la ettringita, formándose en el agua de mar la sal de Friedel, $\left(3 \mathrm{CaO} \cdot \mathrm{Al}_{2} \mathrm{O}_{3}\right.$. . $\mathrm{CaCl}_{2} \cdot 10 \mathrm{H}_{2} \mathrm{O}$ ).

Riedel (44) investiga la resistencia química de morteros fabricados con distintos cementos frente a disoluciones de sulfato de magnesio, deduciendo que dicho ataque, para bajas concentraciones, es función del contenido de $\mathrm{C}_{3} \mathrm{~A}$ del cemento; de tal modo que se comportan mucho mejor cuanto menor es su contenido. Por el contrario, para fuertes concentraciones el cemento portland, independientemente de su composición mineralógica, permanece estable ya que se forma rápidamente yeso en grandes cantidades y otros productos geliformes en las zonas externas atacadas que impiden la penetración de los iones de la disolución y, por consiguiente, el ataque posterior.

En resumen, el ataque químico de los morteros y hormigones producido por agua de mar es un proceso complejo que, fundamentalmente, se debe a la existencia de $\mathrm{Mg}$ (II) y $\mathrm{SO}_{4}$ (II), como probó Vicat en 1818 (3), los cuales forman $\mathrm{Mg}(\mathrm{OH})_{2}$ y $\mathrm{CaSO}_{4}$. La presencia de iones cloruro favorece la resistencia química del cemento portland al ataque de los sulfatos del agua de mar, inhibiendo la formación de ettringita y facilitando su solubilidad 
que, a su vez, se incrementa por la presencia de $\mathrm{Na}$ (I), lo que hace que el agua de mar sea menos agresiva que el conjunto de las disoluciones independientes que tengan cada una de las sales presentes en el mar.

La acción del $\mathrm{CO}_{2}$ disuelto en el agua de mar, a pesar de encontrarse en pequeña cantidad, produce una carbonatación gradual que forma una película superficial de $\mathrm{CaCO}_{3}$, la cual actúa como medio protector. Cuando los compuestos $\mathrm{Mg}(\mathrm{OH})_{2}$ y $\mathrm{CaSO}_{4}$ se forman en cantidades apreciables en las zonas superficiales atacadas del hormigón, los poros se colmatan, se produce una capa superficial que impide la penetración de los iones y que continúe el ataque.

El ataque químico mencionado tiene lugar, para un mismo hormigón, en grado variable según en donde se encuentre situado (sumergido total o parcialmente, zona de mareas, etc.), de tal modo que a estos fenómenos se pueden sumar otros de tipo mecánico, físico y/o biológico.

Todo ello hace que la composición mineralógica del clínker, el tipo de cemento, la fabricación y dosificación del hormigón, las condiciones climáticas y las del medio en donde se encontrará el elemento estructural correspondiente jueguen un papel importante en el comportamiento químico de los cementos frente al agua de mar; hechos que han obligado a que en determinados países existan las especificaciones oportunas.

\section{PARTE EXPERIMENTAI}

\subsection{Cementos estudiados}

En este trabajo se han estudiado dos cementos portland, fabricados por la industria española, que responden a las características, determinadas de acuerdo con la técnica de trabajo descrita en el RC-75 (45), que se incluyen en las tablas 1 y 2.

Los valores correspondientes a la composición química, referidos a la muestra seca a $105^{\circ}-110^{\circ} \mathrm{C}$, se han expresado, en $\%$ en peso, como óxidos excepto la pérdida por calcinación y el residuo insoluble.

\subsection{Agua de mar}

Como medio potencialmente agresivo se ha utilizado agua de mar con el contenido de $\mathrm{Ca}$ (II), $\mathrm{Mg}$ (II), $\mathrm{SO}_{4}$ (II) y $\mathrm{Cl}$ (I) que se señala en la tabla 3.

\subsection{Técnica operatoria}

Basándose en el ensayo acelerado de Koch-Steinegger, utilizado para determinar la capacidad de resistencia química de los cementos de un modo especial frente a la acción agresiva de los sulfatos, se estudia el comportamiento de los morteros (1:3) de los cementos mencionados frente al agua de mar, determinando la evolución de las resistencias mecánicas a flexotracción y de los coeficientes de corrosión de dichos morteros, así como la variación de la concentración iónica de las disoluciones en donde se han conservado su- 
mergidas las probetas de mortero y. la composición estructural de los compuestos que aparecen en la fase sólida formada y de la pasta enriquecida de cemento hidratado, extraída de los morteros.

\section{Variación de las resistencias mecánicas}

Con cada uno de los cementos se han preparado seis series de probetas de mortero de $1 \times 1 \times 6 \mathrm{~cm}$, con relaciones cemento/arena $=1 / 3$ y $a / c=0,60$, que se han conservado durante 24 horas en una cámara húmeda a $20^{\circ} \pm 1^{\circ} \mathrm{C}$ con una humedad relativa superior a $95 \%$, y posteriormente hasta 22 días bajo agua. Una vez transcurrido este período de tiempo, tres series (cada serie consta de 10 probetas) se han sumergido en el agua de mar situada en otros tantos envases estancos y las otras tres series en agua filtrada; la temperatura ambiente es asimismo $20^{\circ} \pm 1^{\circ} \mathrm{C}$. El volumen de líquido ha sido $800 \mathrm{ml}$.

Como arena se ha utilizado la fracción de la arena normalizada, según RC-75, que tiene un tamaño de grano comprendido entre 1 y $1,5 \mathrm{~mm}$.

A las edades de $22+7,22+28$ y $22+56$ días se han determinado las resistencias a flexotracción de cada serie y los coeficientes de corrosión $R_{\mathrm{t}} / R_{\mathrm{t}}$, en donde:

$R_{\mathrm{t}}=$ Resistencia a flexotracción de las probetas sumergidas en agua de mar durante 7,28 y 56 días.

$R_{\mathrm{t}}^{\prime}=$ Resistencias a flexotracción de las probetas sumergidas en agua filtrada, a las edades mencionadas.

$R_{\mathrm{t}}$ y $R_{\mathrm{t}}^{\prime}=$ Media aritmética de los valores correspondientes a las diez probetas.

\section{Variación de la concentración iónica}

El contenido de los iones $\mathrm{Ca}$ (II), $\mathrm{Mg}$ (II), $\mathrm{SO}_{4}$ (II) y $\mathrm{Cl}$ (I), así como la alcalinidad total, en el agua de mar y en las disoluciones, a la edad de 56 días, se ha determinado por técnicas analíticas complexométricas, gravimétricas y volumétricas.

\section{Estudio por difracción de rayos $\mathrm{X}$}

El estudio de la pasta enriquecida correspondiente a los morteros y de las fases sólidas formadas se ha hecho por difracción de rayos X, utilizando un equipo Philips PW-1010, con una unidad de registro PW 1540, trabajando en las siguientes condiciones:

Anodo de cromo $; \mathrm{kV}=40 ; \mathrm{mA}=24$; Rater meter $=8$; Time constant $=2$; Multiplier $=1$; velocidad de goniómetro $=2 \%$ minuto; velocidad de la carta $=40$.

\section{Preparación de la pasta enriquecida}

De uno de los prismas de mortero de las series, fabricadas con ambos cementos, sumergidas durante 56 días en agua de mar y durante el mismo período de tiempo en agua filtrada, se ha separado, una vez desecado a la temperatura ambiente en un recinto con atmósfera inerte, por disgregación mecánica la casi totalidad de la fracción correspondiente a la arena. El residuo, pasta enriquecida, se ha porfirizado y llevado a un portamuestras de difracción de rayos $\mathrm{X}$. 
Preparación de la fase sólida

La fase sólida formada en los medios en donde han estado sumergidas las probetas durante 56 días, se ha separado por filtración y secado con una corriente de nitrógeno, determinando a continuación, por difracción de rayos $\mathrm{X}$, los compuestos cristalinos que existen.

\section{RESULTADOS Y DISCUSION}

\subsection{Caracteristicas de los cementos estudiados}

La composición química y potencial calculada (Bogue) de los dos cementos, así como las resistencias mecánicas de las probetas de los morteros normalizados se encuentran en las tablas 1 y 2.

\section{TABLA 1}

Composición química y potencial de los cementos

Valores (en \% en peso) referidos a la muestra seca a $105^{\circ}-110^{\circ} \mathrm{C}$

\begin{tabular}{|c|c|c|}
\hline \multirow{2}{*}{ Determinaciones } & \multicolumn{2}{|c|}{ Cemento } \\
\hline & 1 & 2 \\
\hline Pérdida por calcinación, P.F. & 0,7 & 1,8 \\
\hline Residuo insoluble, R.I. & 0,2 & 0,9 \\
\hline Dióxido de silicio, $\mathrm{SiO}_{2}$ & 19,6 & 18,8 \\
\hline Oxido férrico, $\mathrm{Fe}_{2} \mathrm{O}_{3}$ & 3,3 & 5,0 \\
\hline Oxido de aluminio, $\mathrm{Al}_{2} \mathrm{O}_{3}$ & 4,4 & 4,6 \\
\hline Oxido de calcio, $\mathrm{CaO}$ & 63,2 & 61,8 \\
\hline Oxido de magnesio, $\mathrm{MgO}$ & 3,2 & 2,3 \\
\hline Trióxido de azufre, $\mathrm{SO}_{3}$ & 3,1 & 4,1 \\
\hline Oxido de calcio libre, $\mathrm{CaO}$ & 0,6 & 0,7 \\
\hline Composición potencial calculada (Bogue) & & \\
\hline Silicato tricálcico, $\mathrm{C}_{3} \mathrm{~S}$ & 65,3 & 58,6 \\
\hline Silicato bicálcico, $\mathrm{C}_{2} \mathrm{~S}$ & 6,8 & 9,8 \\
\hline Aluminato tricálcico, $\mathrm{C}_{3} \mathrm{~A}$ & 6,1 & 3,9 \\
\hline Ferritoaluminato tetracálcico, $\mathrm{C}_{4} \mathrm{AF}$ & 10,0 & 15,2 \\
\hline Sulfato de calcio, $\mathrm{CaSO}_{4}$ & 5,3 & 6,9 \\
\hline
\end{tabular}

El cemento 1 tiene $65,3 \%$ de $\mathrm{C}_{3} \mathrm{~S}, 6,1 \%$ de $\mathrm{C}_{3} \mathrm{~A}$ y $10,0 \%$ de $\mathrm{C}_{4} \mathrm{AF}$ (calculados), mientras que el cemento 2 tiene $58,6 \%, 3,9 \%$ y $15,2 \%$ respectivamente. Las resistencias mecánicas del cemento 1 son mayores que las correspondientes al cemento 2 .

Las fases cristalinas a base de aluminatos, de ambos cementos, son distintas como puede apreciarse en la figura 1. 
TAB L A 2

Resistencias mecánicas de los cementos $\left(\mathrm{kp} / \mathrm{cm}^{2}\right)$

\begin{tabular}{|c|c|c|}
\hline \multirow{2}{*}{ Resistencias mecánicas } & \multicolumn{2}{|c|}{ Cemento } \\
\hline & 1 & 2 \\
\hline \multicolumn{3}{|l|}{ Flexotracción: } \\
\hline 3 días & 60 & 36 \\
\hline 7 días & 66 & 47 \\
\hline 28 días & 80 & 64 \\
\hline \multicolumn{3}{|l|}{ Compresión: } \\
\hline 3 días & 315 & 200 \\
\hline 7 días & 346 & 267 \\
\hline 28 días & 447 & 396 \\
\hline
\end{tabular}

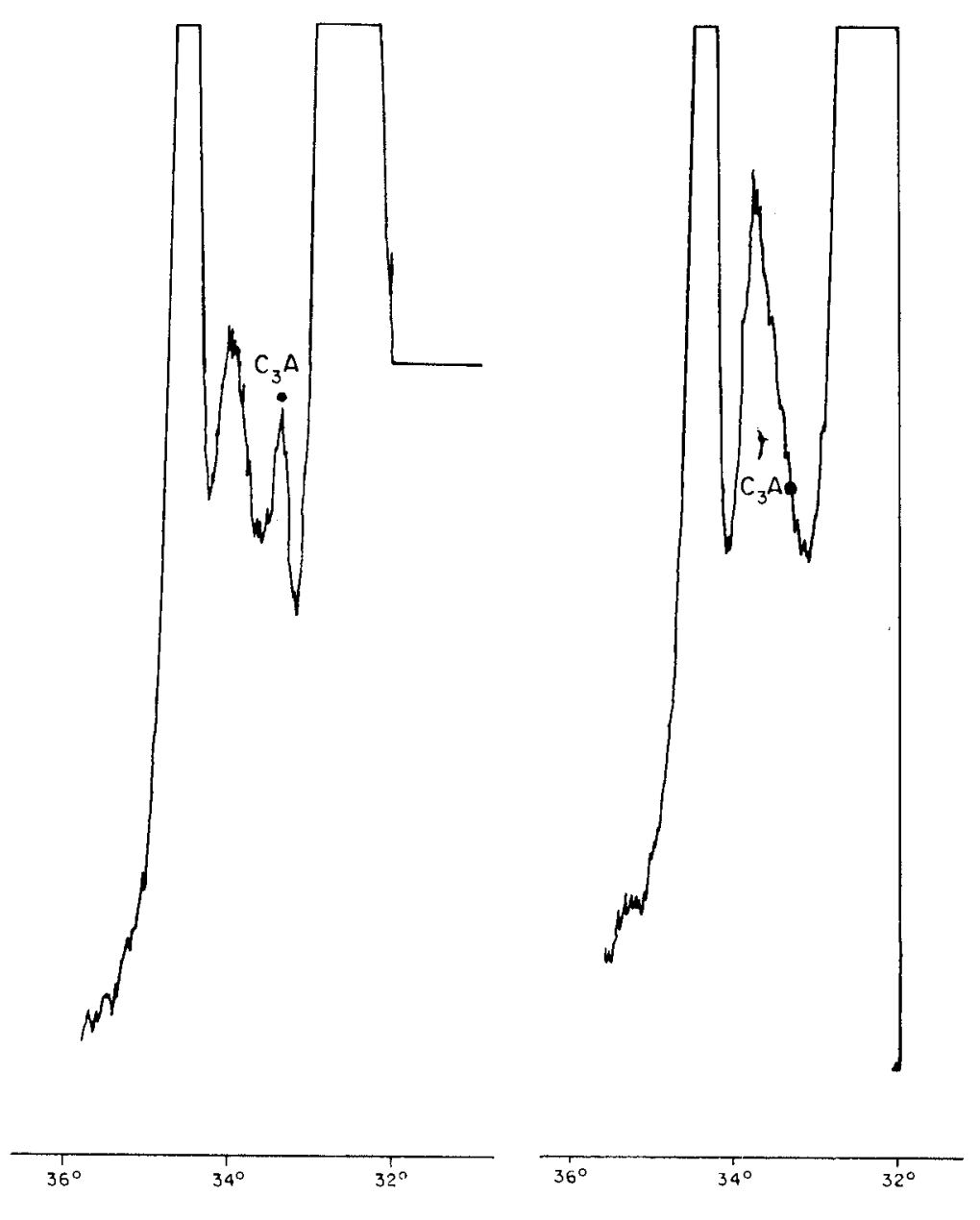

Fig. 1.-DRX de Ios cementos anhidros. 


\subsection{Variación de las resistencias a flexotracción (*)}

Los resultados, media de 10 valores concordantes que corresponden a las 10 probetas de cada serie, se han representado en la figura 2.

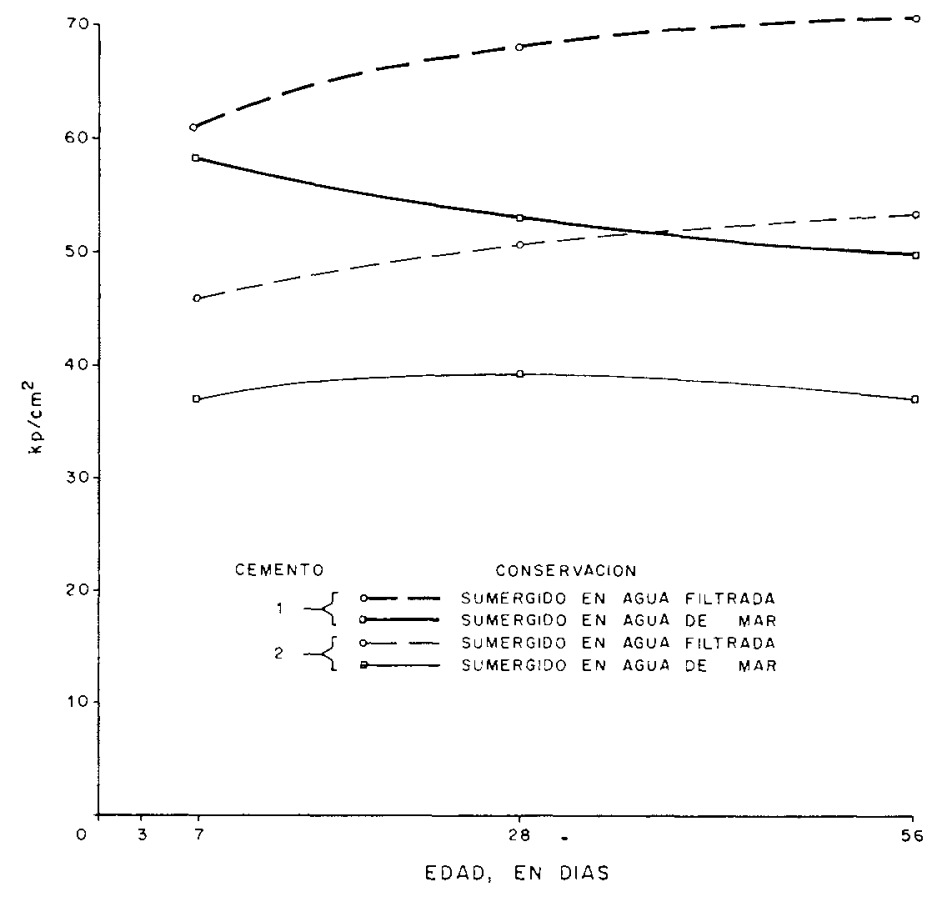

Fig. 2.-Resistencias a flexotracción $\left(\mathrm{kp} / \mathrm{cm}^{2}\right)$.

Las resistencias de las probetas conservadas en agua filtrada aumentan conforme lo hace el tiempo de conservación; los valores más altos corresponden a las probetas de mortero hechas con el cemento 1 . Por el contrario, las resistencias de las probetas de mortero sumergidas en el agua de mar correspondientes al cemento 1 experimentan una disminución del $12 \%$, a 28 días, y del $15,5 \%$, a 56 días, con relación a los valores a 7 días; las resistencias de las probetas de mortero fabricadas con el cemento 2 permanecen prácticamente constantes en las tres edades consideradas.

En la figura 3 se encuentran representados los coeficientes de corrosión de ambos cementos, a las tres edades. Las probetas de mortero fabricadas con el cemento 1 experimentan, con relación al coeficiente a la edad de 7 días, una disminución del 22 y $27 \%$ a las edades de 28 y 56 días, respectivamente; sin embargo, para las probetas del cemento 2 la disminución es 5 y $13 \%$. Los valores de dichos coeficientes a 28 y 56 días son del mismo orden para ambos cementos $(0,76$ y $0,71 / 0,70)$. Se considera, de acuerdo con el método de KochSteinegger, que un cemento es resistente a los sulfatos cuando $R_{t} / R_{t}$, para $t=56$ días, es $\geqslant 0,70$.

(*) Dadas las dimensiones de las probetas no se han determinado las resistencias mecánicas a compresión. 


\subsection{Estudio de la concentración iónica del medio}

Los valores correspondientes al contenido de $\mathrm{Ca}$ (II), $\mathrm{Mg}$ (II), $\mathrm{SO}_{4}$ (II), $\mathrm{Cl}$ (I), expresados en $\mathrm{mg} / \mathrm{l}$ y a la alcalinidad total del medio, en $\mathrm{mM} / l$ de $\mathrm{OH}$ (I), al cabo de 56 días, de los sistemas mortero cemento 1-agua filtrada, mortero cemento 2-agua filtrada, mortero cemento 1-agua de mar, mortero cemento 2-agua de mar, se incluyen en la tabla 3. En los cuatro casos considerados ha aparecido, durante los 56 días, una nueva fase sólida formada por los compuestos que se indican en la tabla 4 y que se señalan en los difractogramas de las figuras $4 \mathrm{a}, 4 \mathrm{~b}$ y $5 \mathrm{a}, 5 \mathrm{~b}$. En la tabla 4 se incluyen, a título orientativo, la intensidad de uno de los picos característicos de los compuestos cristalinos reseñados, así como la cantidad de fase sólida $(\mathrm{mg} / \mathrm{l})$.

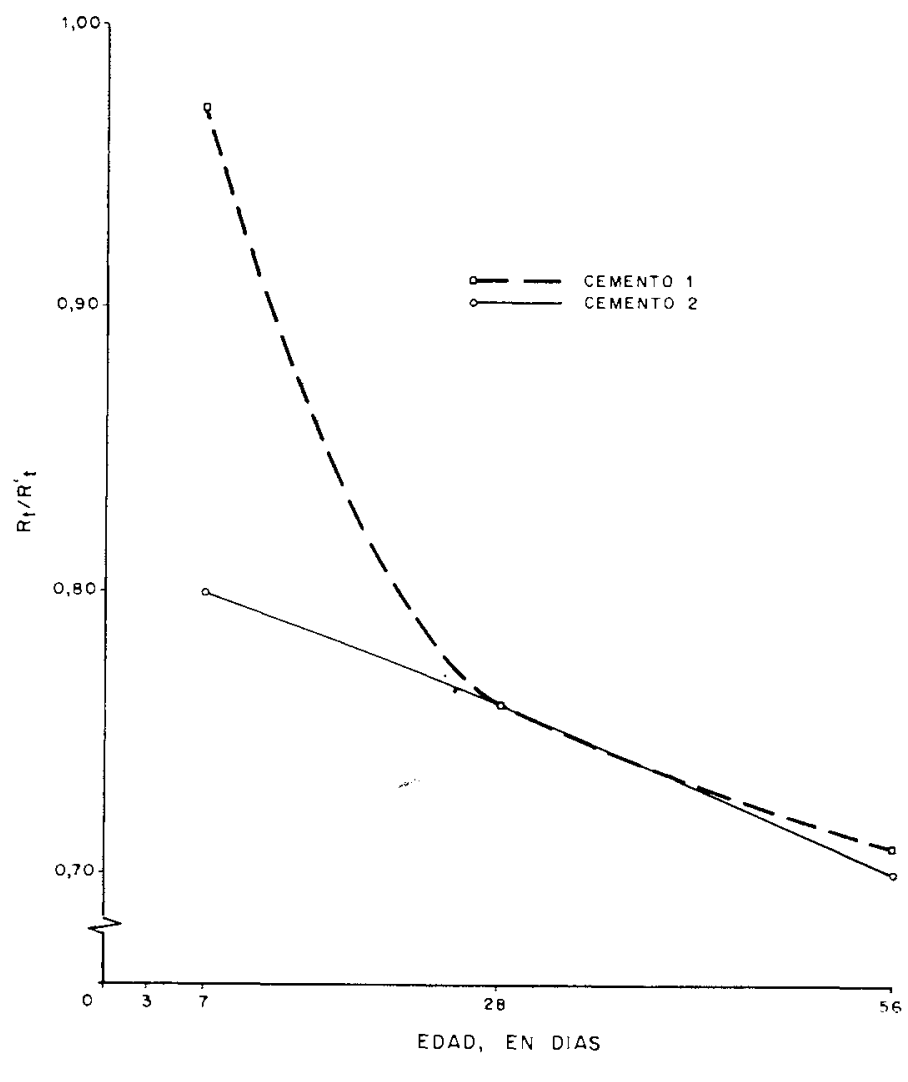

rig. 3.-Evolución de los coeficientes de corrosión.

Sistemas: mortero-agua filtrada

Al cabo de estar sumergidas las probetas 56 días en agua filtrada, una vez curadas durante 22 días, existen en la misma $317 \mathrm{mg} / l$ de Ca (II) para el cemento 1 y $540 \mathrm{mg} / \mathrm{l}$ para el cemento 2 (tabla 3). Del mismo modo hay una fase sólida, en ambos casos, formada por $\mathrm{CaCO}_{3}$ (figuras 4a y 4b), que se presenta como calcita $(669 \mathrm{mg} / l$ y $778 \mathrm{mg} / \mathrm{l}$, tabla 4). La alcalinidad total, expresada como $\mathrm{mM} / l$ de $\mathrm{OH}$ (I), es 14,9 y 26,5 , respectivamente. 


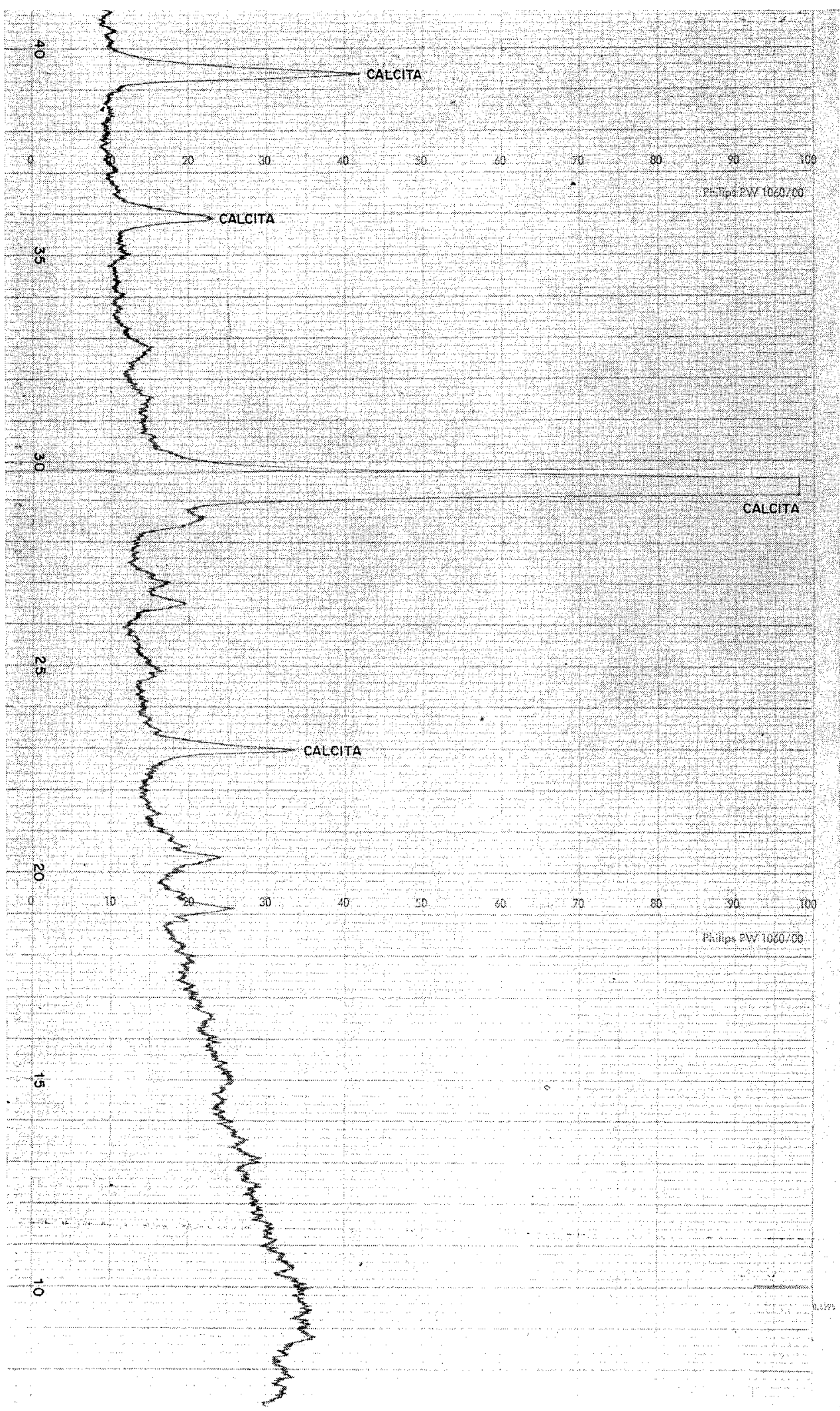

Fig. 4a.-CEMENTo 1. DRX de Ia fase sólida de los sistemas mortero-agua filtrada. 


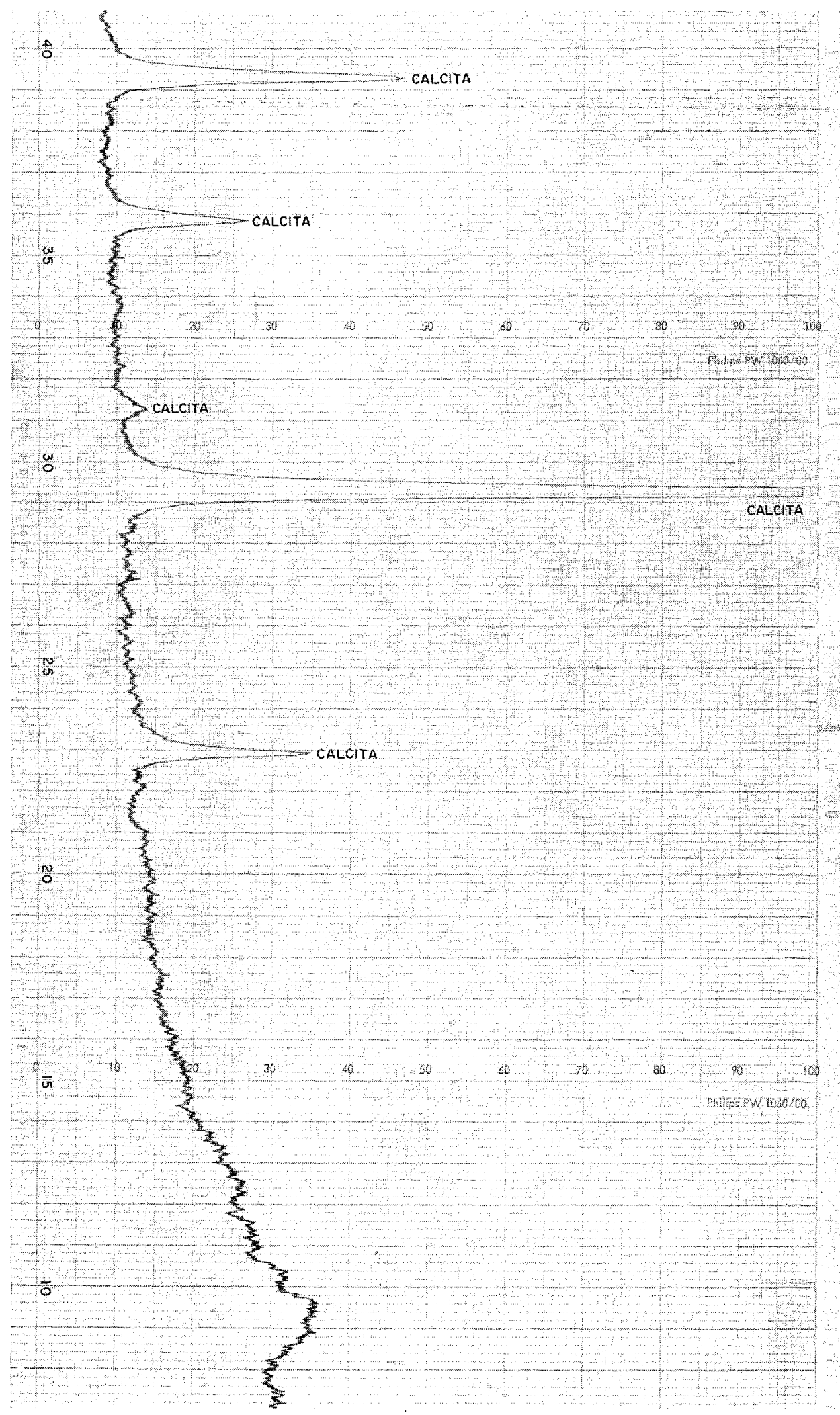

Fig. 4b.-CEMENTo 2. DRX de la fase sólida de los sistemas mortero-agua filtrada. 
T A B L A 3

Sistemas: mortero-agua filtrada y mortero-agua de mar.

Concentración iónica de las disoluciones (mg/l)

\begin{tabular}{|c|c|c|c|c|c|}
\hline \multirow{3}{*}{ Determinación } & \multirow{2}{*}{\multicolumn{2}{|c|}{$\frac{\text { Agua filtrada }}{\text { Cemento }}$}} & \multicolumn{3}{|c|}{ Agua de mar } \\
\hline & & & \multirow{2}{*}{ Original } & \multicolumn{2}{|c|}{ Cemento } \\
\hline & 1 & 2 & & 1 & 2 \\
\hline $\begin{array}{ll}\mathrm{Ca} & \text { (II) } \\
\mathrm{igg} & \text { (II) } \\
\mathrm{SO}_{4} & \text { (II) } \\
\mathrm{Cl} & \text { (I) }\end{array}$ & $\begin{array}{r}317 \\
0 \\
0 \\
0\end{array}$ & $\begin{array}{r}540 \\
0 \\
0 \\
0\end{array}$ & $\begin{array}{r}482 \\
1.402 \\
2.880 \\
20.840\end{array}$ & $\begin{array}{r}2.115 \\
0 \\
1.736 \\
20.631\end{array}$ & $\begin{array}{r}2.162 \\
0 \\
1.925 \\
21.155\end{array}$ \\
\hline $\begin{array}{l}\text { Alcalinidad total, on } \\
\mathrm{mM} / 2 \text { de } \mathrm{OH} \text { (I) }\end{array}$ & 14,9 & 26,5 & 2,6 & 11,1 & 9,3 \\
\hline
\end{tabular}

TA B L A 4

Sistemas: mortero-agua filtrada y mortero-agua de mar.

Fase sólida. Estudio por difración de rayos $\mathrm{X}$ (intensidad en $\mathrm{mm}$ ).

\begin{tabular}{|c|c|c|c|c|c|}
\hline \multirow{3}{*}{ Compuesto } & \multirow{3}{*}{$2 \theta$} & \multicolumn{2}{|c|}{ Agua filtrada } & \multicolumn{2}{|c|}{ Agua de mar } \\
\hline & & \multicolumn{2}{|c|}{ Cemento } & \multicolumn{2}{|c|}{ Cemento } \\
\hline & & 1 & 2 & 1 & 2 \\
\hline $\mathrm{Mg}(\mathrm{OH})_{2}$ & 18,4 & 0 & 0 & 17 & 45 \\
\hline $\mathrm{Na}_{21} \mathrm{MgCl}_{3}\left(\mathrm{SO}_{4}\right)_{10}$ & 26,1 & 0 & 0 & 50 & 57 \\
\hline $\mathrm{CaCO}_{3}$ & 29,4 & $>250$ & $>250$ & 160 & $>250$ \\
\hline Cantidad $n g / l$ & - & 669 & 778 & 957 & 1.326 \\
\hline
\end{tabular}

Como es sabido durante las reacciones de hidratación del cemento portland se forma tobermorita, a partir de $\mathrm{C}_{3} \mathrm{~S}$ y $\mathrm{C}_{2} \mathrm{~S}$, y portlandita, compuesto este último que también se forma a partir del $\mathrm{CaO}$ libre.

La solubilidad del $\mathrm{Ca}(\mathrm{OH})_{2}$, portlandita $(\mathrm{pK}=5,3$ ), en agua es función de la temperatu$\mathrm{ra} ;$ a $20^{\circ} \mathrm{C}$ se disuelven $1.230 \mathrm{mg} / \mathrm{l}$. Esta solubilidad favorece la reacción de hidratación liberándose más $\mathrm{Ca}(\mathrm{OH})_{2}$ que pasa a la disolución en forma iónica con una velocidad progresivamente menor:

$$
\mathrm{Ca}(\mathrm{OH})_{2} \text {.sól. } \Longleftrightarrow \mathrm{Ca}(\mathrm{OH})_{2} \text {.dis. } \Longleftrightarrow \mathrm{Ca}^{2+}+2 \mathrm{OH}^{-}
$$

La disolución progresiva del $\mathrm{Ca}(\mathrm{OH})_{2}$, que produce un incremento de la basicidad del medio, puede dar lugar a la destrucción de los restantes compuestos hidratados, siempre que, en un volumen constante, no se alcance antes la saturación de la disolución. 
La fase sólida, figuras $4 \mathrm{a}$ y $4 \mathrm{~b}$, que aparece en estos sistemas en donde las probetas se encuentran sumergidas en un volumen constante de agua filtrada, está formada por $\mathrm{CaCO}_{3}(\mathrm{pK}=8,3)$ debido a la reacción del $\mathrm{Ca}$ (II), en medio básico, con el $\mathrm{CO}_{2}$ disuelto en el agua, según.

$$
\mathrm{Ca}^{2+}+2 \mathrm{OH}^{-}+\mathrm{CO}_{2} \rightarrow \mathrm{CaCO}_{3}+\mathrm{H}_{2} \mathrm{O}
$$

disminuyendo, cuando hay suficiente $\mathrm{CO}_{2}$, la basicidad del medio. La reacción con el $\mathrm{CO}_{2}$ se favorece conforme se incrementa la cantidad de $\mathrm{Ca}$ (II) en la disolución.

\section{Sistemas: mortero-agua de mar}

En la solubilidad del $\mathrm{Ca}(\mathrm{OH})_{2}$, electrolito débil, influye la presencia de otros iones no comunes, como sucede con el $\mathrm{Na}$ (I), $\mathrm{Cl}$ (I), etc., incrementándola por regla general, fenómeno conocido con el nombre de efecto salino.

Por otra parte, determinados iones no comunes pueden formar compuestos más estables que el $\mathrm{Ca}(\mathrm{OH})_{2}$, sólido, como sucede con el Mg (II), en cuyo caso se desplaza el equilibrio iónico correspondiente, de acuerdo con las siguientes reacciones,

$$
\begin{aligned}
& \mathrm{Ca}(\mathrm{OH})_{2} \text {.sól. } \longleftrightarrow \mathrm{Ca}(\mathrm{OH})_{2} \text {.dis. } \longleftrightarrow \mathrm{Ca}^{2+}+2 \mathrm{OH}^{-}(\mathrm{pK}=5,3), \\
& \mathrm{Mg}^{2+}+2 \mathrm{OH}^{-} \longleftrightarrow \mathrm{Mg}(\mathrm{OH})_{2} \text {.dis. } \longleftrightarrow \mathrm{Mg}(\mathrm{OH})_{2} \text {.sól. }(\mathrm{gK}=11,0),
\end{aligned}
$$

ya que $\left[\mathrm{OH}^{-}\right]$procedente de (A) es mayor que la que precisa la cantidad de $\mathrm{Mg}$ (II) presente en el agua de mar para que se cumpla:

$$
\left[\mathrm{Mg}^{2+}\right]\left[\mathrm{OH}^{-}\right]^{2} \geqslant P_{\mathrm{s}}
$$

E1 $\mathrm{Mg}(\mathrm{OH})_{2}$ sólido formado disminuye la basicidad del medio producida por la solubilidad del $\mathrm{Ca}(\mathrm{OH})_{2}$ y por tanto el valor del $\mathrm{pH}$, en grado distinto según las condiciones, lo que hace que se disuelva más $\mathrm{Ca}(\mathrm{OH})_{2}$, avancen las reacciones de hidratación, continúe la formación de $\mathrm{Mg}(\mathrm{OH})_{2}$ hasta que, en nuestro caso, desaparece el $\mathrm{Mg}$ (II) presente en el agua de mar (tabla 3), incrementándose la cantidad de $\mathrm{Ca}$ (II) en la disolución. El contenido de Ca (II) ha pasado de $482 \mathrm{mg} / \mathrm{l}$ a 2.115 y $2.162 \mathrm{mg} / l$ según se trate del cemento $1 \mathrm{o}$ del cemento 2 , y la alcalinidad ha disminuido con relación a la del medio de los sistemas mortero-agua filtrada.

El $\mathrm{Mg}(\mathrm{OH})_{2}$ sólido se ha detectado en la fase sólida, tabla 4 y figuras $5 \mathrm{a}$ y $5 \mathrm{~b}$, y en la pasta enriquecida de cemento de las probetas de mortero hechas con ambos cementos, tabla 5 y figuras $7 \mathrm{a}$ y $7 \mathrm{~b}$.

La cantidad de $\mathrm{Cl}$ (I) es del mismo orden que la presente en el agua de mar (tabla 3), no habiendo experimentado prácticamente variación en el período de tiempo estudiado (56 días). Unicamente se ha detectado por difracción de rayos $\mathrm{X}$ en el compuesto cristalino D'Ansita que aparece en la fase sólida. $\mathrm{Na}_{21} \mathrm{MgCl}_{3}\left(\mathrm{SO}_{4}\right)_{10}$, en una cantidad análoga tanto para el cemento 1 como para el cemento 2 , tabla 4 y figuras $5 \mathrm{a}$ y $5 \mathrm{~b}$.

El ion $\mathrm{SO}_{4}$ (II) del agua de mar $(2.880 \mathrm{mg} / \mathrm{l})$ experimenta una disminución en la fase líquida en ambos casos $(1.736$ y $1.925 \mathrm{mg} / l)$; se ha identificado por difracción de rayos $\mathrm{X}$ en la fase sóli.da, formando el compuesto cristalino $\mathrm{Na}_{21} \mathrm{MgCl}_{3}\left(\mathrm{SO}_{4}\right)_{10}$, y en la pasta enriquecida de los dos cementos como $\mathrm{CaSO}_{4} \cdot 2 \mathrm{H}_{2} \mathrm{O}$ (figuras $5 \mathrm{a}, 5 \mathrm{~b}$ y $7 \mathrm{a}, 7 \mathrm{~b}$ ). 


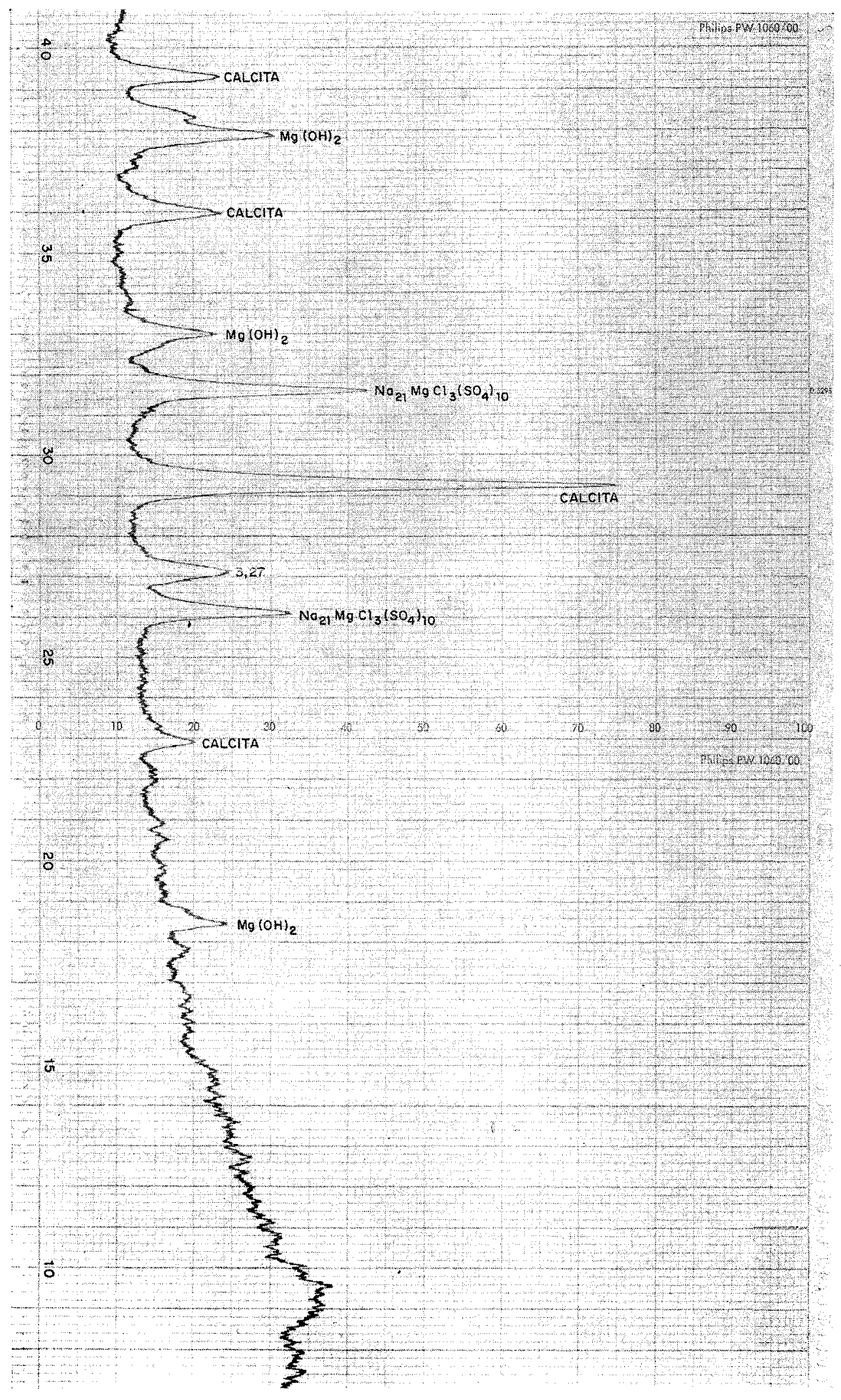

Fig. 5a.-CEMENTo 1. DRX de la fase sólida de los sistemas mortero-agua de mar. 


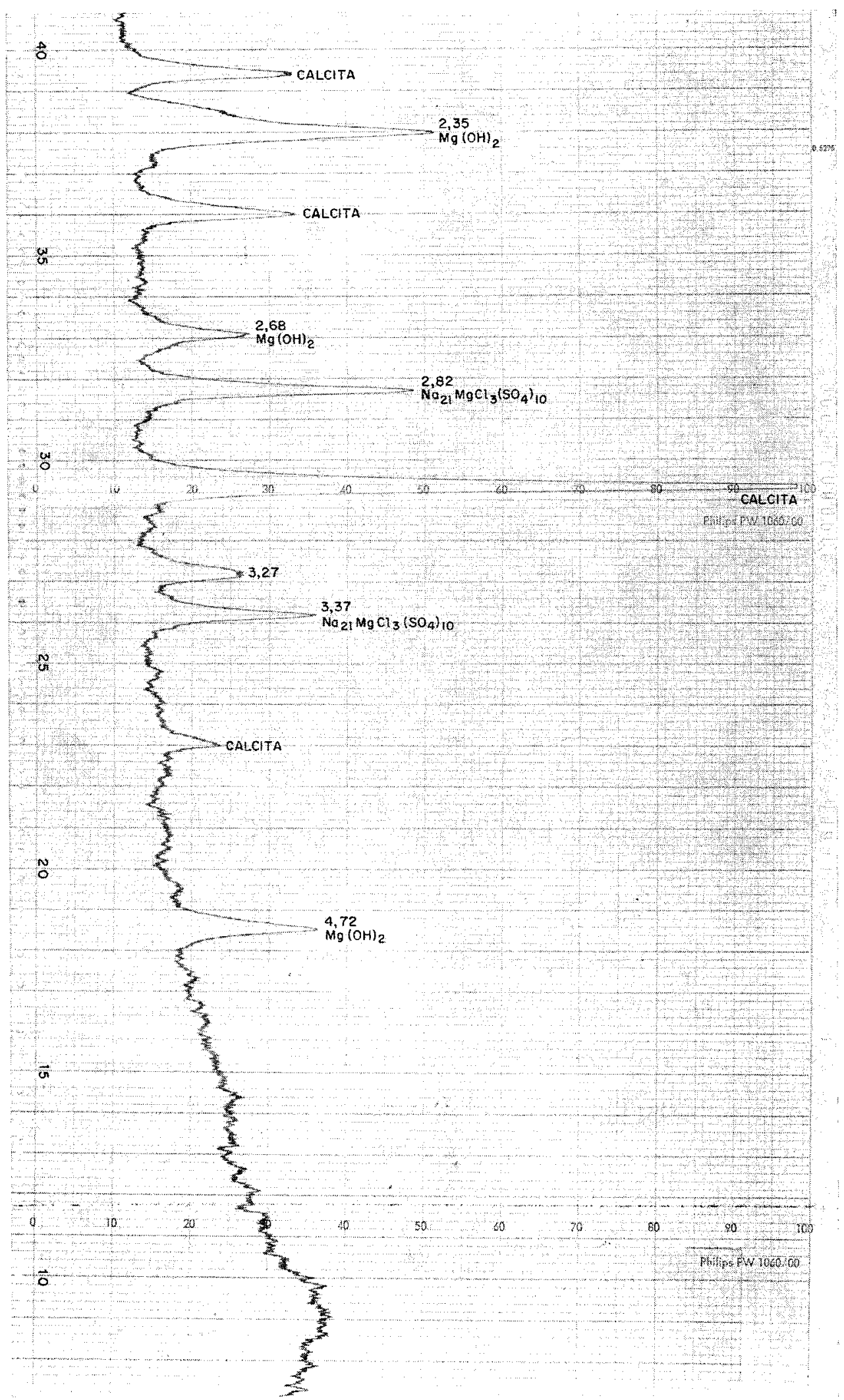

Fig. 5b-CEMENTo 2. DRX de la fase sólida de los distemas mortero-agua de mar. 


\subsection{Estudio de la pasta enriquecida}

El estudio de la pasta enriquecida de cemento, extraída de las probetas de mortero curadas 24 horas en cámara húmeda y 21 días bajo agua filtrada y sumergidas, posteriormente, durante 56 días en agua filtrada, una serie, y en agua de mar otra serie, se ha efectuado por difracción de rayos $\mathrm{X}$.

El aspecto de las probetas de los sistemas mortero-agua filtrada (probetas 1 y 3 ) y mortero-agua de mar (probetas 2 y 4) se puede observar en la figura 8.

\section{T A B L A 5}

Sistemas: mortero-agua filtrada y mortero-agua de mar

Pasta enriquecida. Estudio por difracción de rayos $X$ (intensidad en $\mathrm{mm}$ )

\begin{tabular}{|c|c|c|c|c|c|}
\hline \multirow{3}{*}{ Compuesto } & \multirow{3}{*}{$2 \theta$} & \multicolumn{2}{|c|}{ Agua flltrada } & \multicolumn{2}{|c|}{ Agua de mar } \\
\hline & & \multicolumn{2}{|c|}{ Cemento } & \multicolumn{2}{|c|}{ Cemento } \\
\hline & & 1 & 2 & 1 & 2 \\
\hline $\mathrm{C}_{3} \mathrm{~A} .3 \mathrm{CaSO}_{4} .31 \mathrm{H}_{2} \mathrm{O}$ & 9,0 & 12 & 20 & 25 & 22 \\
\hline $\mathrm{CaSO}_{4} \cdot 2 \mathrm{H}_{2} \mathrm{O}$ & 11,6 & $\mathbf{0}$ & 0 & 10 & 17 \\
\hline $\mathrm{Ca}(\mathrm{OH})_{2}$ & 18,0 & 70 & $>250$ & 45 & 30 \\
\hline $\mathrm{Mg}(\mathrm{OH})_{2}$ & 18,4 & 0 & 0 & 25 & 45 \\
\hline $\mathrm{CaCO}_{3}$ & 29,3 & 16 & 25 & 27 & 45 \\
\hline
\end{tabular}

\section{Sistemas: mortero-agua filtrada}

En las figuras $6 \mathrm{a}$ y $6 \mathrm{~b}$ se incluyen los difractogramas de la pasta enriquecida de cemento extraída de las probetas de mortero hechas con los cementos 1 y 2. Los compuestos cristalinos identificados, así como la intensidad, en $\mathrm{mm}$, de uno de los picos característicos se recogen en la tabla 5 .

En ambos casos se han identificado los siguientes compuestos cristalinos:

a) Ettringita que aparece en cantidad normal, formada en virtud de la reacción:

$$
3 \mathrm{CaO} \cdot \mathrm{Al}_{2} \mathrm{O}_{3} \cdot 12 \mathrm{H}_{2} \mathrm{O}+3\left(\mathrm{CaSO}_{4} \cdot 2 \mathrm{H}_{2} \mathrm{O}\right)+13 \mathrm{H}_{2} \mathrm{O} \rightarrow 3 \mathrm{CaO}_{2} \mathrm{Al}_{2} \mathrm{O}_{3} \cdot 3 \mathrm{CaSO}_{4} \cdot 31 \mathrm{H}_{2} \mathrm{O}
$$

b) Portlandita, $\mathrm{Ca}(\mathrm{OH})_{2}$, procedente de la reacción de hidratación de los silicatos, fundamentalmente, y del $\mathrm{CaO}$ libre. En la pasta del cemento 2 existe mayor cantidad que en la del cemento 1 .

c) Calcita, $\mathrm{CaCO}_{3}$, formado en la reacción del $\mathrm{CO}_{2}$ disuelto en el agua con el $\mathrm{Ca}(\mathrm{OH})_{2}$ presente en la pasta, según:

$$
\mathrm{Ca}(\mathrm{OH})_{2} \text { ).sól. } \stackrel{\mathrm{H}_{2} \mathrm{O}}{\longleftrightarrow} \mathrm{Ca}(\mathrm{OH})_{2} \cdot \text { dis. } \stackrel{\mathrm{H}_{2} \mathrm{O}}{\Longleftrightarrow} \underbrace{\stackrel{\mathrm{OH}^{-}}{\mathrm{C}_{2}}}_{\begin{array}{c}
\mathrm{Ca}_{2} \\
\downarrow \\
\mathrm{CaCO}_{3} . \text { sól. }+\mathrm{H}_{2} \mathrm{O}
\end{array}}
$$




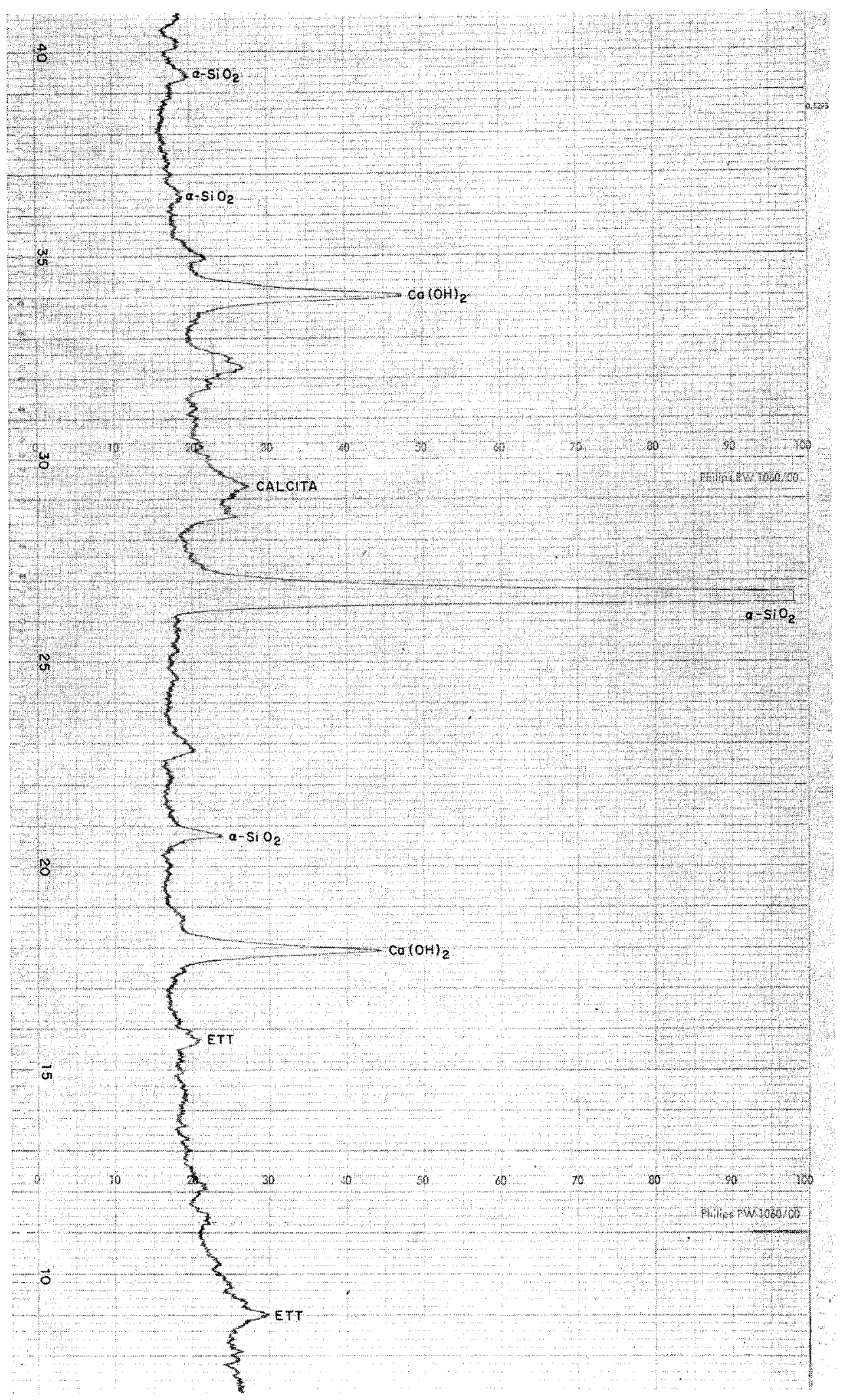

Fig. 6a.-CEMENTo 1 . DRX de la pasta enriquecida de los sistemas mortero-agua filtrada. 


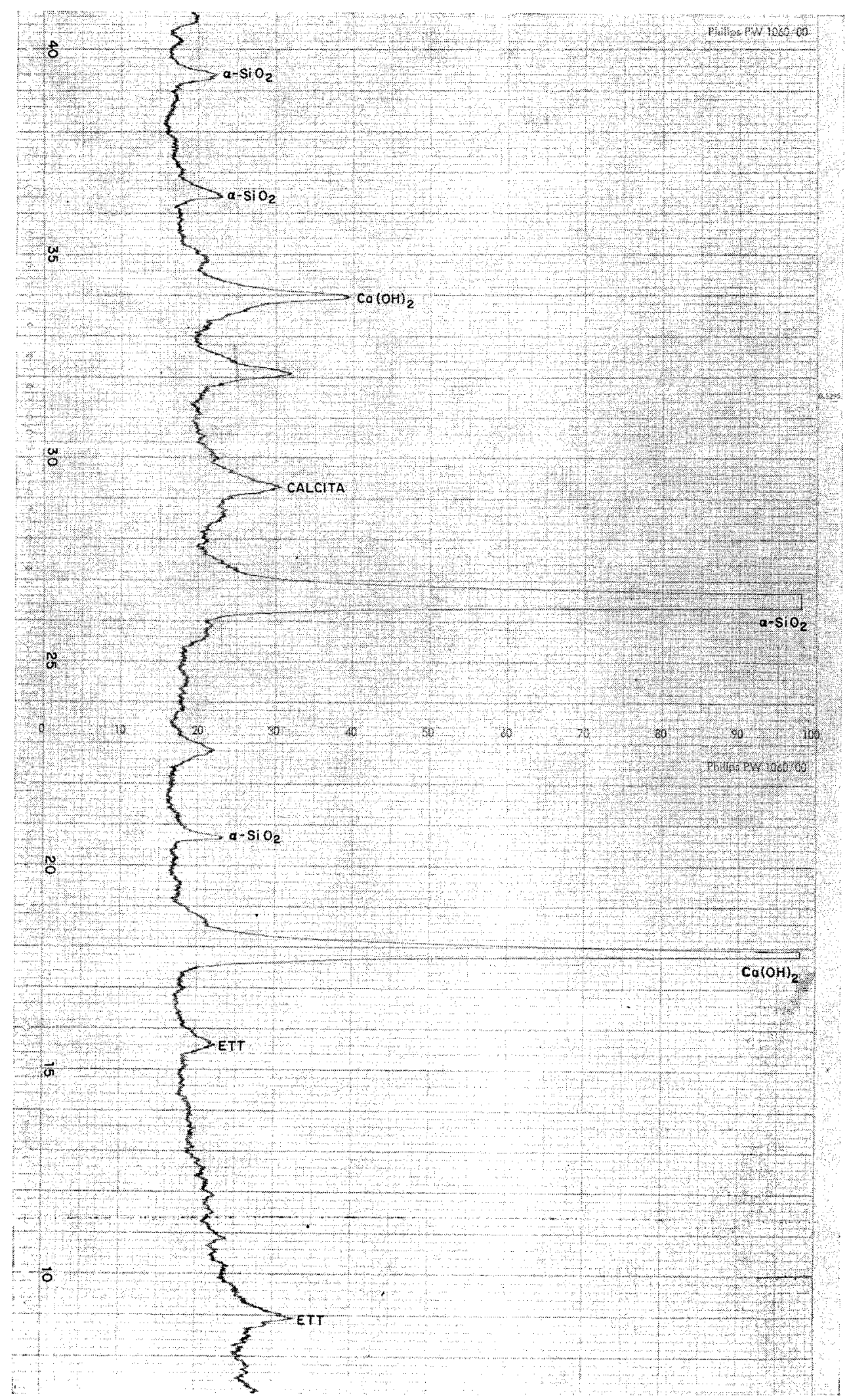

Fig. 6b-CEMENTo 2. DRX de la pasta enriquecida de los sistemas mortero-agua filtrada. 
produciéndose una disminución del $\mathrm{pH}$. La reacción tiene lugar, en una primera etapa, en la zona superficial de las probetas como puede apreciarse en la figura 8 (probeta 1 , y fundamentalmente probeta 3 ), actuando de capa protectora.

El $\mathrm{CaCO}_{3}(\mathrm{pK}=8,3)$ es más estable en medio acuoso que el $\mathrm{Ca}(\mathrm{OH})_{2}$ ( $\mathrm{pK}=5,3$ ), lo que hace que al proseguir la reacción de carbonatación avance la de hidratación produciendo, entre otros productos, más $\mathrm{Ca}(\mathrm{OH})_{2}$. La cantidad que existe de $\mathrm{Ca}(\mathrm{OH})_{2}$ en la pasta del cemento 2 es de consideración, mientras que en la del cemento 1 es de pequeña magnitud.

\section{Sistemas: mortero-agua de mar}

En las figuras 7 a y $7 \mathrm{~b}$ se encuentran los difractogramas de la pasta enriquecida de cemento extraída de las probetas de mortero hechas con los cementos 1 y 2 ; los compuestos cristalinos identificados, así como la intensidad de uno de los picos característicos se incluyen en Ia tabla 5 .

Los compuestos cristalinos identificados, en ambos casos, han sido los siguientes:

a) Ettringita que aparece en una cantidad del mismo orden que en el caso de las probetas fabricadas con el cemento 2 sumergidas en agua filtrada.

b) Portlandita, $\mathrm{Ca}(\mathrm{OH})_{2}$, procedente de la reacción de hidratación de los silicatos, fundamentalmente, y del $\mathrm{CaO}$ libre. La cantidad es menor que en el caso de las probetas sumergidas en agua filtrada.

c) Calcita, $\mathrm{CaCO}_{3}$, formada, como en el caso del sistema mortero-agua filtrada, por reacción del $\mathrm{Ca}(\mathrm{OH})_{2}$ con el $\mathrm{CO}_{2}$ disuelto en el agua de mar.

d) Brucita, $\mathrm{Mg}(\mathrm{OH})_{2}$, formada por reacción del $\mathrm{Ca}(\mathrm{OH})_{2}$ presente en la pasta de cemento hidratado y el $\mathrm{Mg}$ (II) en el agua de mar según:

$$
\mathrm{Ca}(\mathrm{OH}_{2} \text {.sól. } \stackrel{\mathrm{H}_{2} \mathrm{O}}{\longleftrightarrow} \mathrm{Ca}(\mathrm{OH})_{2} \text {.dis. } \stackrel{\mathrm{H}_{2} \mathrm{O}}{\Longleftrightarrow} \underbrace{\mathrm{Ca}^{2+}+2 \mathrm{OH}^{-}}_{\begin{array}{c}
+ \\
\mathrm{Mg}^{2+} \\
\downarrow \\
\mathrm{Mg}(\mathrm{OH})_{2} \text {.sól. }
\end{array}}
$$

reacción que produce los fenómenos señalados en el apartado 4.3.

e) Yeso, $\mathrm{CaSO}_{4} \cdot 2 \mathrm{H}_{2} \mathrm{O}$, formado en cantidades relativamente bajas; es el compuesto detectado que se encuentra en menor cantidad.

Consideramos que el $\mathrm{CaSO}_{4} \cdot 2 \mathrm{H}_{2} \mathrm{O}(\mathrm{pK}=4,6)$ se forma por reacción con el $\mathrm{Ca}(\mathrm{OH})_{2}$ $(\mathrm{pK}=5,3)$ presente en la pasta con el ion $\mathrm{SO}_{4}$ (II) procedente del agua de mar, teniendo en cuenta la disminución del $\mathrm{pH}$ y el incremento de $\mathrm{Ca}(\mathrm{OH})_{2}$ al formarse el $\mathrm{Mg}(\mathrm{OH})_{2}$ (pK $\left.=11,0\right)$, en virtud de las reacciones:

$$
\begin{gathered}
\mathrm{Ca}\left(\mathrm{OH}_{2} \text {.sól. } \stackrel{\mathrm{H}_{2} \mathrm{O}}{\longleftrightarrow} \mathrm{Ca}(\mathrm{OH})_{2} \text {.dis. } \stackrel{\mathrm{H}_{2} \mathrm{O}}{\stackrel{\mathrm{Ca}^{2+}+2 \mathrm{OH}^{-}}{+}}\right. \\
\begin{array}{c}
\mathrm{Mg}^{2+}+\mathrm{SO}_{4}{ }^{2-} \\
\downarrow
\end{array} \\
\mathrm{Mg}(\mathrm{OH})_{2} \text {.sól. }+\mathrm{CaSO}_{4} \cdot 2 \mathrm{H}_{2} \mathrm{O} . \text { sól. }
\end{gathered}
$$

desapareciendo por cada mol de $\mathrm{CaSO}_{4} \cdot 2 \mathrm{H}_{2} \mathrm{O}$ que se forma, con un volumen molecular de $74,3 \mathrm{~cm}^{3}$, otro de $\mathrm{Ca}(\mathrm{OH})_{2}$ con un volumen molecular de $33,2 \mathrm{~cm}^{3}$; reacción que va acompañada de un incremento de volumen. 


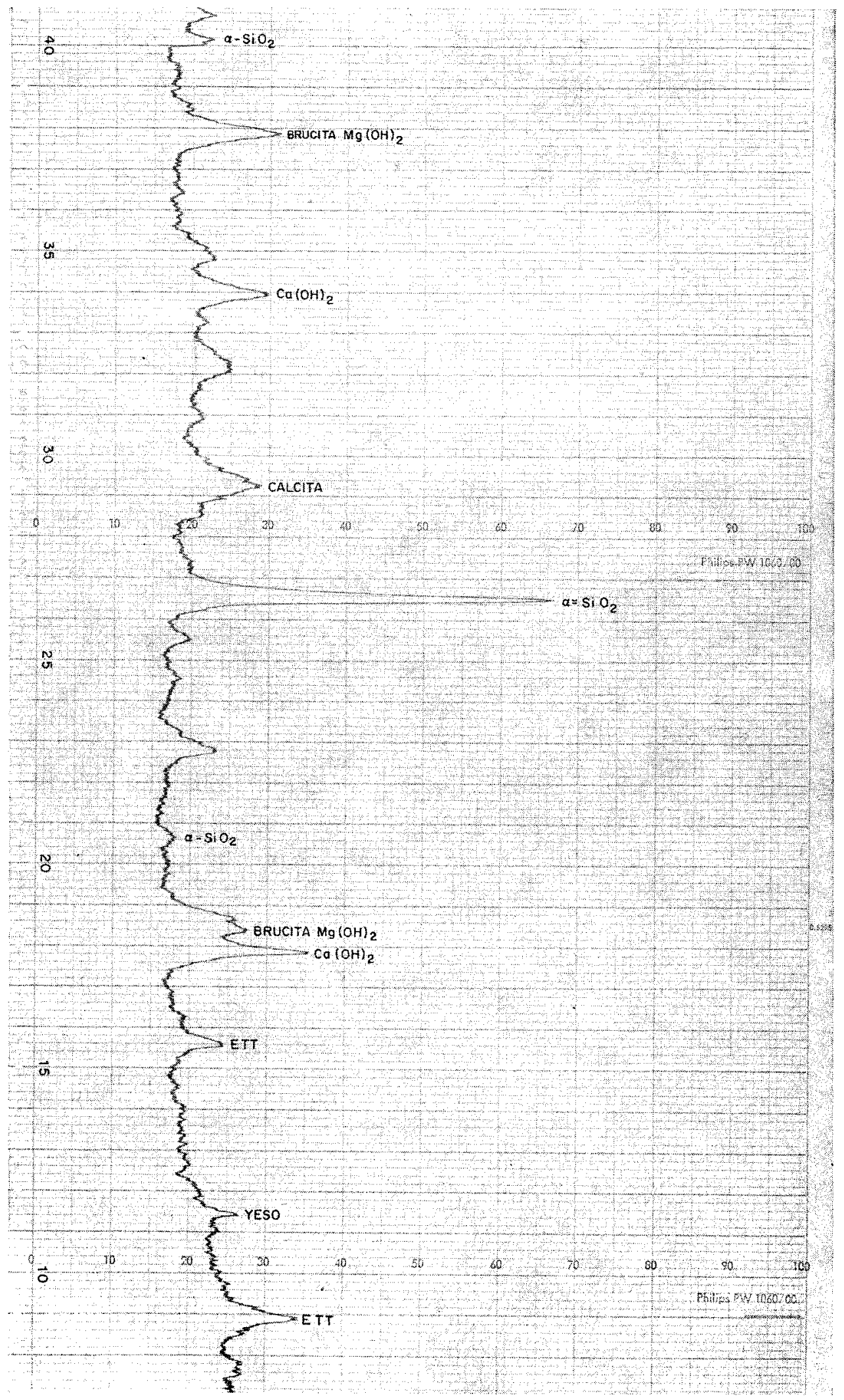

Fig. 7a.-CEMrNTo 1 . DRX de Ia pasta enriquecida de los sistemas mortero-agua de mar. 


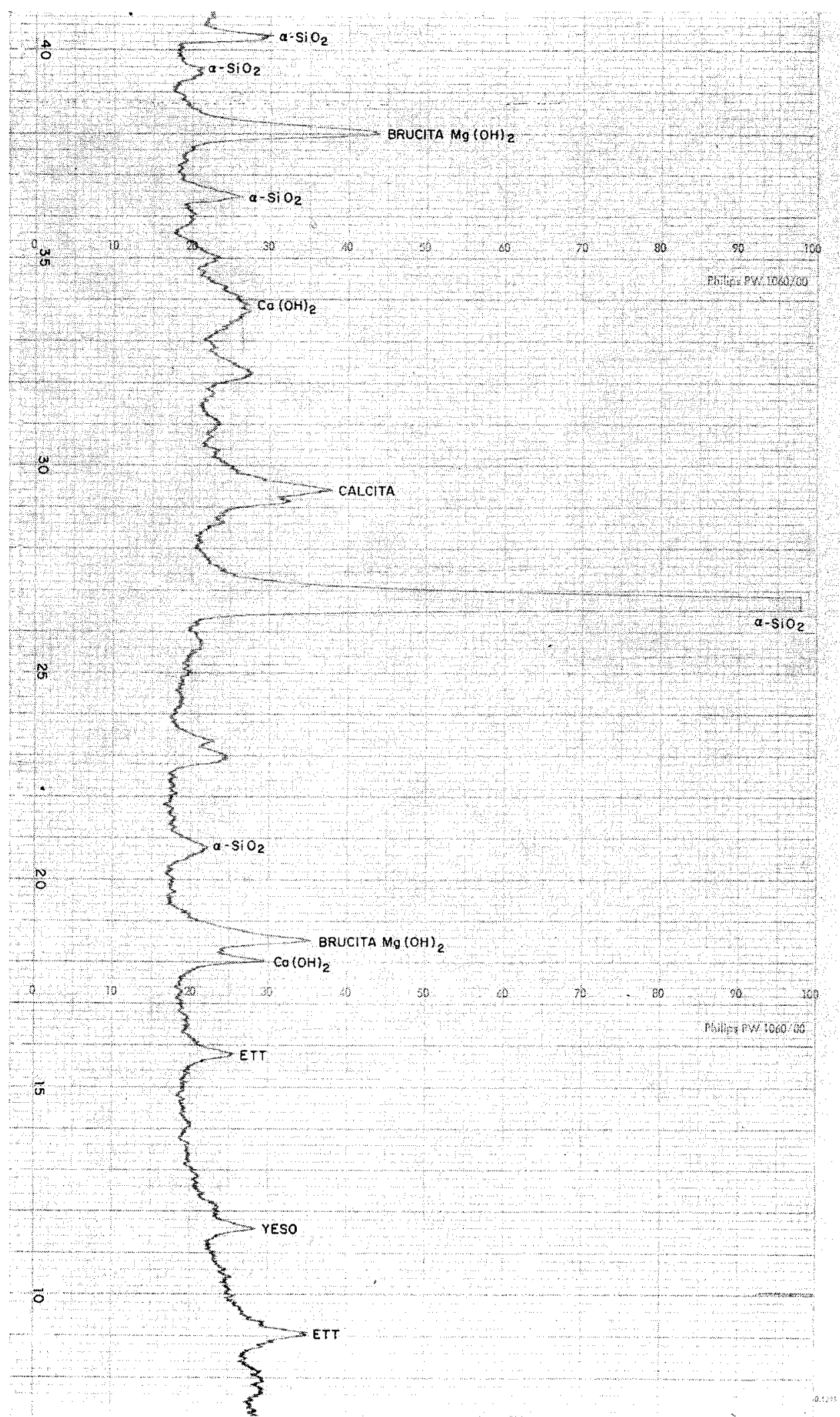

Fig. 7b.-CEMENTO 2. DRX de la pasta enriquecida de los sistemas mortero-agua de mar. 
La formación y precipitación de los compuestos $\mathrm{CaCO}_{3}, \mathrm{Mg}(\mathrm{OH})_{2}$ y $\mathrm{CaSO}_{4} .2 \mathrm{H}_{2} \mathrm{O}$, fundamentalmente de los dos primeros, tiene lugar en la zona superficial de las probetas (probetas 2 y 4 de la figura 8) avanzando lentamente hacia el interior produciendo la colmatación de los poros $\mathrm{y}$, consiguientemente, una disminución de la permeabilidad y un aumento de la resistencia química.

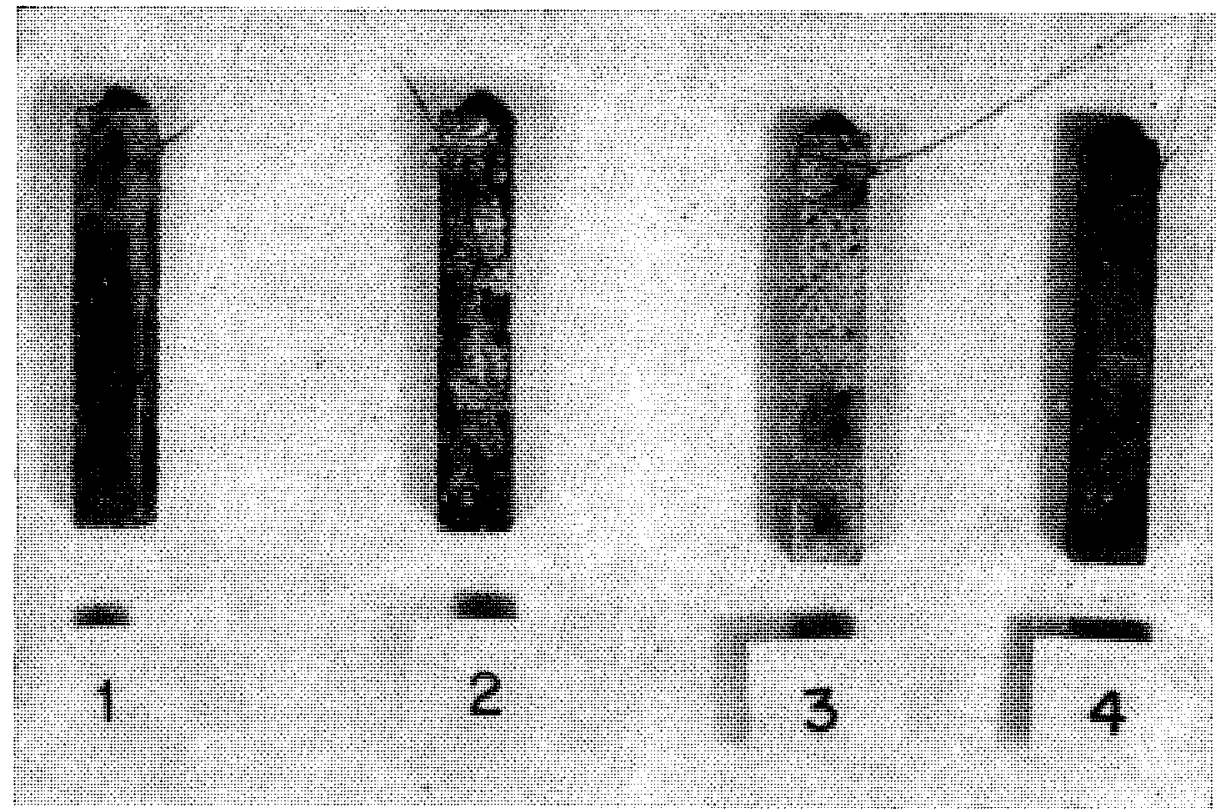

Fìg. 8

1. Mortero cemento 2 -agua filtrada.

2. Mortero cemento 2 -agua de mar.
3. Mortero cemento 1 -agua filtrada.

4. Mortero cemento 1 -agua de mar.

\section{RESUMEN Y CONCLUSIONES}

En el presente trabajo se da cuenta del comportamiento de los morteros (1:3) hechos con dos cementos portland españoles, que responden a la siguiente composición potencial calculada (Bogue),

$$
\begin{aligned}
& \text { Cemento 1: } \mathrm{C}_{3} \mathrm{~S}=65,3 \% ; \mathrm{C}_{2} \mathrm{~S}=6,8 \% ; \mathrm{C}_{3} \mathrm{~A}=6,1 \% ; \mathrm{C}_{4} \mathrm{AF}=10,0 \%, \\
& \text { Cemento 2: } \mathrm{C}_{3} \mathrm{~S}=58,6 \% ; \mathrm{C}_{2} \mathrm{~S}=9,8 \% ; \mathrm{C}_{3} \mathrm{~A}=3,9 \% ; \mathrm{C}_{4} \mathrm{AF}=15,2 \%,
\end{aligned}
$$

sumergidos en agua de mar, habiendo determinado la evolución de las resistencias mecánicas a flexotracción de las probetas de $1 \times 1 \times 6 \mathrm{~cm}$ y de los coeficientes de corrosión (Koch-Steinegger), así como la variación de la concentración iónica del agua filtrada y dei agua de mar en donde se han sumergido las probetas durante 56 días, la composición estructural de la fase sólida formada y de la pasta enriquecida de cemento.

Las probetas de mortero se han curado durante 24 horas en recinto estanco a $20^{\circ} \pm 1^{\circ} \mathrm{C}$ con una humedad relativa superior a $95 \%$ y, posteriormente, hasta 21 días bajo agua; a continuación se han sumergido en agua filtrada, unas series, y en agua de mar, otras series, que se encontraban en recipientes estancos; la temperatura ambiente ha sido $20^{\circ} \pm$ $\pm 1^{\circ} \mathrm{C}$. 
A partir de los datos experimentales se han obtenido las siguientes conclusiones:

\section{Primera:}

Las resistencias mecánicas a flexotracción de las probetas de mortero del cemento 1, sumergidas en agua de mar, experimentan una disminución, conforme aumenta el tiempo de inmersión (7, 28 y 56 días) mientras que las del cemento 2 permanecen prácticamente constantes; por el contrario, las resistencias de las probetas conservadas durante el mismo período de tiempo bajo agua filtrada, aumentan con el tiempo de conservación $(22+7,22+28$ y $22+56$ días $)$.

Los coeficientes de corrosión, a 56 días, de ambos cementos son análogos $(0,70$ y 0,71$)$.

\section{Segunda:}

La composición química del agua de mar, en donde han estado sumergidas las probetas de ambos cementos, experimentan cambios dignos de consideración que afectan principalmente al contenido de $\mathrm{Mg}$ (II), Ca (II) y $\mathrm{SO}_{4}$ (II); de tal modo que para los dos cementos el primero llega a desaparecer, el segundo sufre un incremento superior al $300 \%$ y el tercero una disminución mayor del $35 \%$. Por el contrario, el contenido de $\mathrm{Cl}$ (I) permanece prácticamente constante.

El agua filtrada, en la que se han conservado las probetas durante 56 días, presenta 317 y $540 \mathrm{mg} / \mathrm{l}$ de Ca (II), según se trate del cemento 1 o del 2.

\section{Tercera:}

Tanto en el agua de mar, como en el agua filtrada, en donde han estado sumergidas las probetas de mortero durante 56 días, aparece una fase sólida en la que se han identificado los compuestos cristalinos brucita, calcita y D'Ansita en el primer caso y calcita en el segundo.

La fase sólida formada es mayor en los sistemas mortero-agua de mar que morteroagua filtrada. La cantidad de dicha fase sólida que corresponde al agua de mar o agua filtrada en donde se han conservado las probetas del cemento 2 es superior $(\sim 40 \% \mathrm{y}$ $16 \%$, respectivamente) a la del cemento 1 .

\section{Cuarta:}

La composición estructural de la pasta enriquecida de cemento hidratado extraída de las probetas sumergidas en agua de mar experimenta, asimismo, cambios de consideración. Se han identificado por DRX los compuestos cristalinos ettringita en cantidad normal, yeso, portlandita, brucita y calcita.

En la pasta enriquecida de las probetas conservadas en agua filtrada, durante el mismo tiempo se han identificado ettringita en cantidad normal, portlandita y calcita, en mayor cantidad en la pasta del cemento 2 .

\section{Quinta:}

El ataque químico de la pasta de cemento hidratado de las probetas de mortero por el agua de mar (sumergidas durante 56 días) es complejo. En este caso, se debe fundamentalmente a las reacciones del $\mathrm{Mg}$ (II) $\mathrm{y}$, en menor grado, del $\mathrm{SO}_{4}$ (II) presentes en el agua de mar, que han dado lugar a la formación de $\mathrm{Mg}(\mathrm{OH})_{2}$ y $\mathrm{CaSO}_{4} \cdot 2 \mathrm{H}_{2} \mathrm{O}$ en la pasta de cemento y de $\mathrm{Mg}(\mathrm{OH})_{2}$ y $\mathrm{Na}_{21} \mathrm{MgCl}_{3}\left(\mathrm{SO}_{4}\right)_{10}$ en la nueva fase sólida. Por otra parte, el $\mathrm{CO}_{2}$ disuelto en el agua reacciona con el $\mathrm{Ca}(\mathrm{OH})_{2}$ de la pasta y el $\mathrm{Ca}(\mathrm{OH})_{2}$ de la disolución, en medio básico, produciendo $\mathrm{CaCO}_{3}$. 
Los compuestos que aparecen en la pasta enriquecida de cemento se han formado, especialmente, en las zonas superficiales de las probetas, actuando como medio protector que impide la penetración de los iones del agua de mar y que continúe el ataque químíco.

\section{B I B L I O G R A F I A}

(1) Idonn, G. M.: Durabilité des Bétons. Colloque Int. RILEM. Praga (1962), págs. 351-355.

(2) Bogue, R. H.: La Quimica del Cemento. Edit. Dossat. Madrid (1952), págs. 572-573.

(3) LeA, F. M. y Desch, E. H.: Quimica del Cemento y del Hormigón. Tipografia Artística. Madrid (1960), págs. 639-649.

(4) Biczok, I.: La corrosión del hormigón y su protección. Edic. Urmo, Bilbao (1972), págs. 148-151.

(5) LeA, F. M. y DeSch, E. H.: Loc. cit., págs. 340-354 y 633-648.

(6) Nicol, A.: Rev. Mat. de Const., 414, 74-76, (1950).

(7) Duriez, M.: Travaux, 221, 189-199, (1953); 222, 259-265, (1953); 223, 285-290, (1953); 224, 319-327, (1953); 225, 349-353, (1953).

(8) Campts, F.: Silic. Ind., 2, 79-88, (1963); e Int. Jymp. RILEM, "Durability of Concrete"; Rapport Prelim.; Praha (1961), págs. 90-102.

(9) Anonimo: Note d’Inf. Techn. 57 del Cent. Scient. Tech. de la Const.; Bruselas, (1966), jágs. 14.

(10) Garcta de Paredes, P.: Monografía n.० 232. IETcc; Madrid (1963).

(11) Brocard, J. et Cirodde, R.: Bull. RILEM, 32, 323-329. (1966).

(12) Brocard, J. et Cirodde, R.: Int. Symp. RILEM, "Durability of Concrete"; Final Rep. Praha, (1962), páginas 285-293.

(13) LYSE, I.: Int. Symp. RILEM, "Durability of Concrete"; Rapport. Prel.; Praha, (1961), págs. 183-191.

(14) Courcambeck, P.; Duhoux, L. et Tessier, A.: Int. Symp. RILEM, "Durability of Concrete"; Rapport Prel.; Praha, (1961), págs. 233-247.

(15) WESCHE, K.: Bull. RILEM, 32, 291-293, (1966).

(16) Wesche, K. and MANGEL, S.: Bull. RILEM, 32, 295-297, (1966).

(17) GJöRv, O. E.; GukILd, I. and SundH, H. P.: Bull. RILEM, 32, 305-322, (1966).

(18) GJönv, O. E.: Durability of Reinforced Concrete Wharves in Norwegian Harbours. Edit. Ingeniërforlaget A/S, Oslo, (1968); págs. 157-159.

(19) SmolczYк. H. G.: Bull. RILEM, 32, 299-304, (1966).

(20) Duhoux, L. et Tessier, A.: Bull. RILleM, 32, 268-278, (1966).

(21) DURIEz, M.; según LEA, F. M.: Bull. RILEM, 30, 59-60, (1966).

(22) Rio, A. et Celani, A.; según Lea, F. M.: Bull. RILEM, 30, 62-63, (1966).

(23) Temutasse, M.; van Bemst, A. et de Keyser, W. L.; según Lea, F. M.: Bull. RILeM, 30, 64, (1966).

(24) Sousa Coutinho, A. de et Peres Rodrigues, F. M. según Lea, F. M.: Bull. RILEM, 30, 65, (1966).

(25) Nielsen, K. E. C.; según LeA, F. M.: Bull. RILEM.; según LEA, F. M.: Bull. RILEM, 30, 65, (1966).

(26) Kuenning, W. H.: Highway Res. Rec., 113, 43-87, (1966).

(27) Mather, B.: Highway Res. Rec., 113, 33-42, (1966).

(28) KREMSER, H.: Zement-Kalk-Gips, 3, 134-137, (1968).

(29) Dutron, R. et Plisnier, J.: Cent. Nat. de Rech. Scient. et Techn. pour L'Ind. Ciment; RR-CRIC-28-f(1970).

(30) KalouseK, G. L. and Beton, E. J.: J. Amer. Conc. Inst.; 67-9, 187-192, (feb. 1970).

(31) Steopoe, A.: La durabilité du béton. Edit. Eyrolles, París (1970), págs. 151 a 157.

(32) BiczoK, I.: Loc. cit., págs. 291-296.

(33) GJöRv, O. E.: J. Amer. Conc. Inst., 1, 60-67 (1971).

(34) Peltier, R.: Rev. des Mat., 680, 31-44, (1973).

(35) BAsILIO, F. DE A.: Conferencia pronunciada en la Universidad Federal de Brasilia, (1974).

(36) Gerwick, B. C.: Handbook of Conc. Eng.; Fintel, M. Van Nostrand, Reinhold, Co.; New York (1974), págs. 617-619.

(37) Anonimo: Handbook of Conc. Eng.; Fintel, M.; Van Nostrand, Reinhold Co.; New York (1974), página 178.

(38) Regourd, M.; Hornain, H. et Mortureux, B.: Rev. des Mat., 687, 67-79, (1974).

(39) Regourd, M.: Ann. Inst. Techn. du Bât. et des Trav. Public., 329, 86-102, (1975).

(40) Coliepardi, M.; Guelia, S. M. e Valente, M.: L'Ind. Ital del Cemento, 10, notiz. 5-9, (1967).

(41) Della Libera, G.: L'Ind. del Cemento, 11, notiz. 4-8, (1976).

(42) Dzulynski, M.: Comunicación RILEM-4CDC-Durabilité des bétons. (1976).

(43) Locher, F.: Proceed. of the Fifth Int. Symp. on the Chem. of Cement. Tokio, (1968); págs. 328-335.

(44) RIEDEL. W.: Zement-Kalk-Gips, 6, 286-296, (1973).

(45) RC-75: MOP. Madrid, (1975). 